\title{
Refinement of Mean Dynamic Topography Over Island Areas Using Airborne Gravimetry and Satellite Altimetry Data in the Northwestern South China Sea
}

Wu, Yihao; Abulaitijiang, Adili; Andersen, Ole Baltazar; He, Xiufeng; Luo, Zhicai; Wang, Haihong

Published in:

Journal of Geophysical Research: Solid Earth

Link to article, DOI:

10.1029/2021JB021805

Publication date:

2021

Document Version

Publisher's PDF, also known as Version of record

Link back to DTU Orbit

Citation (APA):

Wu, Y., Abulaitijiang, A., Andersen, O. B., He, X., Luo, Z., \& Wang, H. (2021). Refinement of Mean Dynamic Topography Over Island Areas Using Airborne Gravimetry and Satellite Altimetry Data in the Northwestern South China Sea. Journal of Geophysical Research: Solid Earth, 126(8), [e2021JB021805].

https://doi.org/10.1029/2021JB021805

\section{General rights}

Copyright and moral rights for the publications made accessible in the public portal are retained by the authors and/or other copyright owners and it is a condition of accessing publications that users recognise and abide by the legal requirements associated with these rights.

- Users may download and print one copy of any publication from the public portal for the purpose of private study or research.

- You may not further distribute the material or use it for any profit-making activity or commercial gain

- You may freely distribute the URL identifying the publication in the public portal 


\section{JGR Solid Earth}

\section{RESEARCH ARTICLE \\ 10.1029/2021JB021805 \\ Key Points: \\ - The direct application of a high- degree global geopotential model (GGM) may cause errors exceeding $6 \mathrm{~cm}$ in MDT determination \\ - Altimetry data alone is insufficient for high-accuracy mean dynamic topography (MDT) recovery over island areas \\ - Airborne surveys may be necessary for MDT recovery with centimeter- level accuracy over coastal/island areas}

Correspondence to:

Y. Wu,

yihaowu@hhu.edu.cn

Citation:

Wu, Y., Abulaitijiang, A., Andersen, O. B., He, X., Luo, Z., \& Wang, H. (2021). Refinement of mean dynamic topography over island areas using airborne gravimetry and satellite altimetry data in the northwestern South China Sea. Journal of Geophysical Research: Solid Earth, 126, e2021JB021805. https://doi. org/10.1029/2021JB021805

Received 3 FEB 2021

Accepted 6 AUG 2021
(C) 2021. American Geophysical Union. All Rights Reserved.

\section{Refinement of Mean Dynamic Topography Over Island Areas Using Airborne Gravimetry and Satellite Altimetry Data in the Northwestern South China Sea}

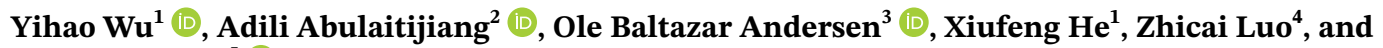 \\ Haihong Wang ${ }^{5}$ (i) \\ ${ }^{1}$ School of Earth Sciences and Engineering, Hohai University, Nanjing, China, ${ }^{2}$ Institute of Geodesy and \\ Geoinformation, University of Bonn, Bonn, Germany, ${ }^{3}$ DTU Space, Technical University of Denmark, Lyngby, \\ Denmark, ${ }^{4} \mathrm{MOE}$ Key Laboratory of Fundamental Physical Quantities Measurement, School of Physics, Huazhong \\ University of Science and Technology, Wuhan, China, ${ }^{5}$ School of Geodesy and Geomatics, Wuhan University, Wuhan, \\ China
}

Abstract The determination of high-quality mean dynamic topography (MDT) over island areas faces multiple challenges, due to the error in a global geopotential model (GGM) as well as the contaminated waveforms of satellite altimetry data and scarcity of surveyed gravimetric observations. We study the potential to enhance regional quasi-geoid/MDT over island areas by using recently released satellite altimetric gravity data and airborne gravimetric observations. Numerical experiments over the Paracel Islands in the northwestern South China Sea show that the combination of airborne gravity data enhances the local gravity field, and reduces the errors in the associated quasi-geoid, in comparison to the result directly derived from a GGM. The results demonstrate that the direct application of a GGM may cause significant oscillations in MDT determination over island areas, by a magnitude exceeding $6 \mathrm{~cm}$. The incorporation of altimetric gravity data slightly reduces these errors; however, the bubble-like errors are prominent, suggesting that altimetry data alone may be insufficient for high-accuracy MDT recovery. In contrast, combining airborne gravity data dramatically reduces these oscillations, by a magnitude of several centimeters, indicating that airborne gravimetric surveys may be necessary for MDT determination with centimeter-level accuracy over coastal/island areas. Further comparison with independent ocean data shows that the geostrophic velocities computed by merging a high-degree GGM and local airborne gravity data can reconstruct real surface ocean circulation; and the GOCE-based (Gravity Field and Steady-State Ocean Circulation Explorer) GGMs may be preferable as the reference models in MDT determination.

Plain Language Summary The information of mean dynamic topography (MDT) is crucial for studying sea level change as well as understanding ocean circulation and its role in the global climate system. The determination of MDT requires accurate knowledge of mean sea surface and quasi-geoid/ geoid models. Unfortunately, these models are usually of low quality over coastal and island areas, leading to the difficulty for MDT determination over these regions. To alleviate this problem, we introduce highresolution airborne gravimetric survey and data derived from the recent satellite altimetry missions to refine local MDT. We study a case over the Paracel Islands in the northwestern South China Sea, and we show that the use of altimetry data alone is insufficient for high-accuracy MDT recovery over costal/island areas. We also show that the combination of airborne data significantly improves the local MDT. Our findings highlight the necessity of using airborne surveys for MDT determination with centimeter-level accuracy over coastal/island areas.

\section{Introduction}

The acquisition of mean dynamic topography (MDT) is beneficial in understanding sea level change, ocean currents, heat/energy cycles, and water exchanges with surrounding regions (e.g., Li et al., 2019; Lyu et al., 2016). The accurate MDT information is also useful in several coastal human activities including fishing, search and rescue, and oil spill monitoring (e.g., Rio et al., 2011, 2014). Moreover, the MDT can be used for height datum unification (Featherstone \& Filmer, 2012; Filmer et al., 2018; Woodworth et al., 2012), 
which is useful for establishing unified vertical reference systems over countries/regions with extensive coastlines and many islands.

The MDT illustrates the removal of the geoid from the mean sea surface (MSS) (Becker et al., 2014; Bingham et al., 2008; Griesel et al., 2012). The abundance of satellite altimetry data enables MSS modeling with an accuracy of approximately 2-6 cm at a mean resolution between 20 and $30 \mathrm{~km}$ over open seas (e.g., Andersen \& Knudsen, 2009; Schaeffer et al., 2012). These improved MSS models emphasize the importance of geoid/ quasi-geoid computation for MDT recovery. Combining MSS data with the satellite-only global geopotential model (GGM), which is derived from the Gravity Recovery and Climate Experiment (GRACE) (e.g., Tapley et al., 2003, 2004) and Gravity Field and Steady-State Ocean Circulation Explorer (GOCE) missions (Bruinsma et al., 2013; Pail et al., 2010, 2011; Rummel et al., 2002), allows global-scale monitoring of the ocean state from space with unprecedented accuracy at long wavelengths (Bingham, Knudsen, et al., 2011; Knudsen et al., 2011; Volkov \& Zlotnicki, 2012).

The recently released satellite-only GGMs that computed with GRACE and GOCE data can be expanded to a full degree and order (d/o) of 300 (Brockmann et al., 2021; Kvas et al., 2021), with a spatial resolution of $\sim 72 \mathrm{~km}$. However, using a satellite-only GGM alone makes it difficult to recover the medium- and short-wavelength signals that have the wavelengths shorter than $\sim 72 \mathrm{~km}$. A filtering procedure is required to match the spectral contents of MSS and a satellite-only GGM (Albertella et al., 2012; Jayne, 2006; Tapley et al., 2003). The high-degree GGMs, such as Earth Gravitational Model 2008 (EGM2008; with a full expansion d/o of 2190/2159) (Pavlis et al., 2012, 2013) and EIGEN-6C4 (d/o 2190/2159) (Förste et al., 2014), were computed by merging satellite gravimetric observations and terrestrial and marine gravity data. These models have relatively high spatial resolutions, and are able to sample the global gravity field at a resolution of $\sim 10 \mathrm{~km}$. As such, the use of a high-degree GGM can dramatically increase the spatial resolution of MDT compared to the one computed from a satellite-only GGM. However, the MDT determined from a high-degree GGM still suffers from significant errors. The commission errors of EGM2008 are about several centimeters in terms of quasi-geoid heights over the major ocean basins (Pavlis et al., 2012). Whereas, the errors of this model reach several decimeters or even meter level over Arctic (McAdoo et al., 2013). In addition, the short-wavelength geoid errors beyond the maximal expansion degree of a high-degree model, that is, the omission errors, which are due to the unresolved short-wavelength signals, may lead to significant high-frequency oscillations in MDT modeling (Farrell et al., 2012; Skourup et al., 2017). As such, the errors in a high-degree GGM remain a barrier for MDT determination with centimeter-level accuracy.

MDT can be enhanced by merging local marine gravity data (Hunegnaw, Hipkin, et al., 2009; Hunegnaw, Siegismund, et al., 2009; Schwabe \& Scheinert, 2014); however, it is difficult to refine the MDT over coastal/ island areas, where the quality of altimetric gravity data suffers from contaminated waveforms and the corruption of associated corrections (e.g., Andersen \& Scharroo, 2011; Deng \& Featherstone, 2006). The scarcity of shipborne surveys further compromises this situation, particularly in narrow coastal regions and shallow oceanic areas (Forsberg et al., 2012; Hipkin et al., 2004; Huang, 2017).

Airborne gravimetry is of great interest for MDT determination over coastal/island areas (Forsberg et al., 2007; Knudsen et al., 2004; Solheim et al., 2007), providing seamless observations over land/island and oceans with consistent precision. Moreover, airborne data is independent of altimetry data sets, which makes it possible to investigate separately the signals introduced from airborne and altimetric gravity data. As such, it may be a tool to overcome the drawbacks of satellite altimetry in regions close to land/island (e.g., Featherstone, 2010; Hwang et al., 2006). Moreover, the recent altimeter measurements from missions, such as CryoSat-2, Jason, and Satellite with Argos and AltiKa (SARAL)/Altika, provide high-quality data, and these data can be used to improve the global marine gravity field (Garcia et al., 2014; Sandwell et al., 2013, 2014). Consequently, the altimetric gravity models computed by combining recent altimetry observations outperform the models computed without these data, even in coastal regions (e.g., Andersen \& Knudsen, 2019).

The application of recent altimetry data has great potential for MDT refinement over coastal zones (Andersen, Nielsen, et al., 2018; Idžanović et al., 2017). Moreover, the wide use of airborne gravimetry provides solid data basis for regional MDT modeling, which may allay the well-known coastal zone problem in quasi-geoid/MDT modeling near land/island (Huang, 2017; Wu et al., 2019). In this study, we focus on regional 


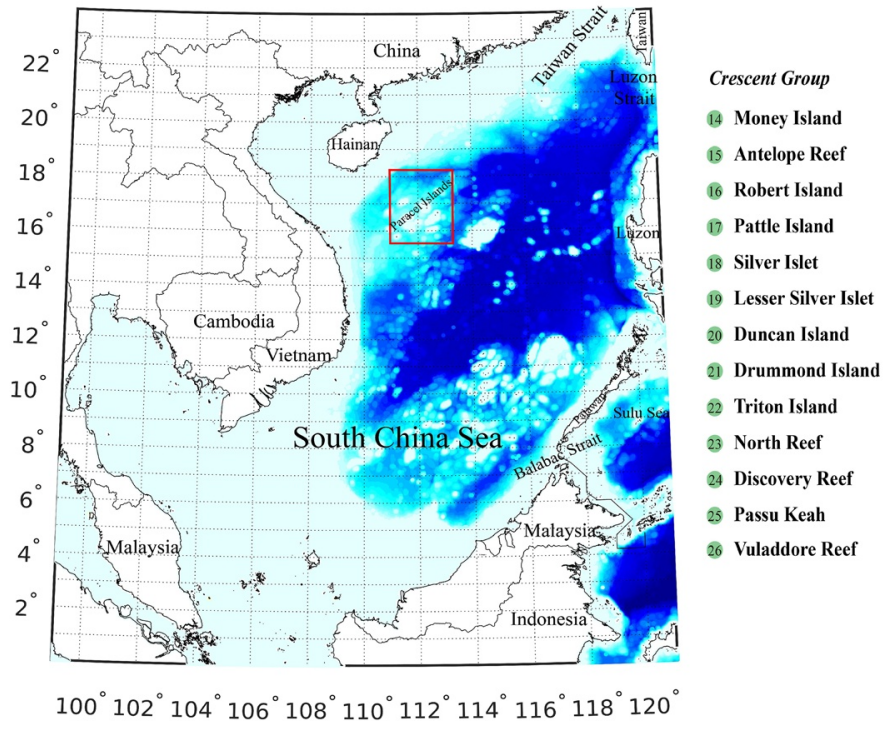

(a)

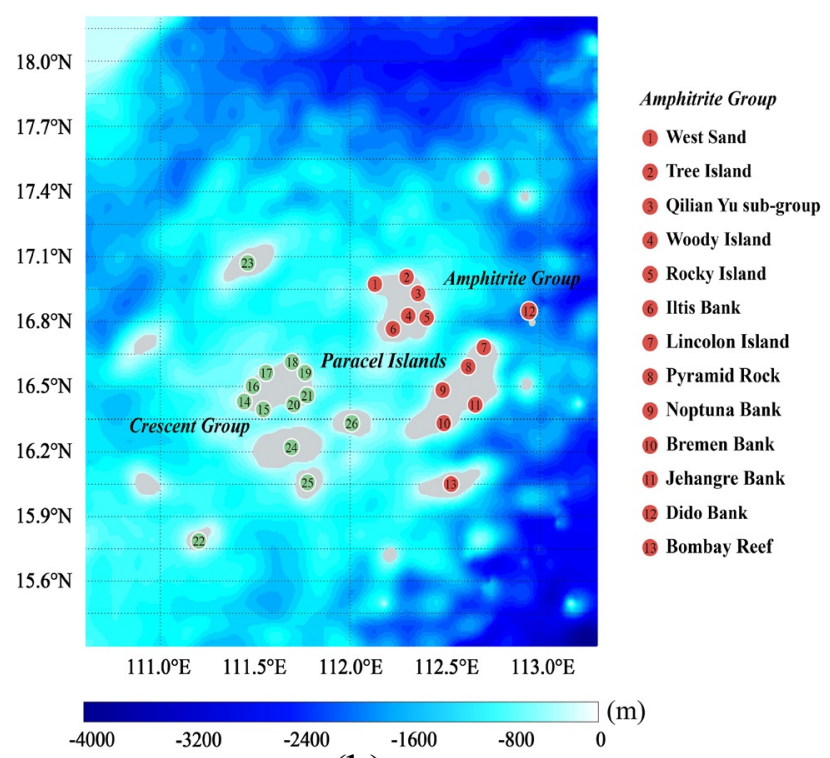

(b)

Figure 1. (a) Location of the Paracel Islands (region enclosed in the red rectangle) over the South China Sea [SCS]; and (b) distribution of the main islands constituting the Paracel Islands.

MDT refinement over island areas, where we study the roles of satellite altimetry and airborne gravimetry in local MDT recovery. Moreover, we investigate the potential to improve local MDT by using altimetric and airborne gravity data.

\section{Study Area and Data}

The study area is the Paracel Islands (known as the Xisha Islands), located in the northwestern South China Sea (SCS) (Figure 1a). The Paracel Islands comprise the Amphitrite and Crescent Groups, comprised islands, reefs, and banks. The Amphitrite Group consists of low narrow islands with sand cays and enclosed shallow lagoons connected by rock reefs. The Crescent Group, approximately $70 \mathrm{~km}$ southwest of the Amphitrite Group, consists of islands and reefs that form a crescent-like structure from west to east (Figure 1b). The background information displayed in Figure 1 shows the local topography and bathymetry derived from the Shuttle Radar Topography Mission (Farr et al., 2007) and the General Bathymetric Chart of the Oceans (Weatherall et al., 2015). The topography and bathymetry heights range from $-3,984$ to $10 \mathrm{~m}$, where positive or negative values represent heights above or below the mean sea level, respectively. Small islands are in abundance in this area and; as such, there are multiple difficulties in high-quality MDT determination. For the purposes of this study, it is a good opportunity to investigate the role of airborne gravimetry in local/regional MDT refinement. An airborne gravimetric survey was conducted by the First Geodetic Surveying Brigade of the Ministry of Natural Resources of China in 2018, offering seamless data coverage over island areas and the ocean. Moreover, a recent altimetry-derived gravity model is also available; the model, DTU17GRA, developed at the National Space Institute at the Technical University of Denmark (DTU space), which focuses on improving the marine gravity field over coastal zones (Andersen \& Knudsen, 2019). The DTU17GRA- and airborne-derived gravity data are applied for local quasi-geoid/ MDT refinement. Sections 2.1 to 2.4 describe the data sets used in this study.

\subsection{Choice of Global Geopotential Models}

The computation of local quasi-geoid/MDT requires a GGM, and three high-degree GGMs are used as the reference models for local MDT modeling, respectively. First, the widely used EGM2008 with a full expansion d/o of 2190/2159 (Pavlis et al., 2012, 2013) is introduced. EGM2008 was computed by merging GRACE measurements with terrestrial gravity data on the land and altimetric gravity data in the ocean. EGM2008 
was developed without GOCE data; as such, two recently released GOCE-based GGMs, the GOCE-EGM2008 combined model (GECO; Gilardoni et al., 2015) and the XGM2019e_2159 (Zingerle et al., 2019), are used. The spectral contents at the frequency bands approximately from degree 30 to 220 in these models are meant to have been substantially improved by GOCE data (Gruber et al., 2014). GECO (d/o 2190/2159) was computed by incorporating the GOCE-only TIM R5 (d/o 250) (Brockmann et al., 2014) solution into EGM2008, where the GOCE-only TIM R5 was developed using satellite-to-satellite tracking data and GOCE gravity gradiometry data over the entire period. XGM2019e_2159 (d/o 2190/2159) is a combined model developed by including GOCO06S in the long wavelength. This was then combined with the marine gravity data from the National Geospatial-Intelligence Agency (NGA) and DTU13GRA data from the DTU space (Andersen et al., 2013) at short wavelengths (Zingerle et al., 2019).

\subsection{Surface Altimetry-Derived Gravity Data}

Surface marine gravity data retrieved from DTU17GRA are used as input data set for local gravity field modeling. DTU17GRA was developed by including 25 years of satellite altimetry data over the ocean. The derivation of DTU17GRA involved combining seven and a half years (2010-2017) of CryoSat-2 data (had completed seven full geodetic cycles), 1 year (2012-2013) of Jason-1 data operated over a 406 d geodetic mission, and 1 year (2016-2017) of SARAL/AltiKa data from the geodetic phase (Andersen \& Knudsen, 2019). The DTU17GRA model (1-arcmin grid spacing) was developed by improving the coastal and Arctic gravity field, which enhances the short wavelengths of the marine gravity field (10-15 km). The comparison with an airborne survey over the north Greenland showed that the standard deviation (SD) of the misfits between DTU17GRA and the airborne data was $3.78 \mathrm{mGal}$. This value increased to 8.81, 5.91, and $5.45 \mathrm{mGal}$ when DTU10GRA, DTU13GRA, and DTU15GRA were evaluated, respectively. The comparison with the marine gravity data from the NGA in the northwest Atlantic Ocean revealed that the accuracy of DTU17GRA/ DTU15GRA was $\sim 2.51 \mathrm{mGal}$; this is better than the previous altimetric gravity field models. For example, in DTU13GRA and DTU10GRA, the accuracy decreased to 2.83 and $3.16 \mathrm{mGal}$, respectively (Andersen \& Knudsen, 2019). As the accuracy of DTU17GRA is inconclusive for the Paracel Islands, we assume a priori accuracy of $3 \mathrm{mGal}$, and the posterior variance factor is estimated by using the Monte Carlo variance component estimation (MCVCE) (Koch \& Kusche, 2002; Kusche, 2003) in local gravity field modeling.

We compare the DTU17GRA-derived gravity anomalies with the values computed from GGMs. To do this, we first extract a grid (1-arcmin grid spacing) that covers the study area from the DTU17GRA model. The DTU17GRA model was input with latitude, longitude, and gravity anomalies, and we use a recently released MSS model, DTU18MSS (Andersen, Knudsen, et al., 2018), to recover the ellipsoidal heights of the points on this grid. Then, we compute the free-air gravity anomalies on this grid based on different GGMs up to the maximum degree, and determine the differences between the DTU17GRA data and GGM-derived values. Figure 2 illustrates these differences, indicating that the DTU17GRA model may include small-scale contents that cannot be resolved from these GGMs. The disparities between EGM2008/GECO and DTU17GRA range from approximately -13.7 to $21.4 \mathrm{mGal}$, with a SD of $\sim 3.1 \mathrm{mGal}$ (see Table 1); and substantial differences are found in regions around the Amphitrite and Crescent Groups. There are reduced discrepancies between XGM2019e_2159 and DTU17GRA compared to EGM2008/GECO, whereby the misfits range from approximately -11.0 to $9.6 \mathrm{mGal}$, with a SD of $\sim 2.1 \mathrm{mGal}$. This may be attributed to the use of different data in developing EGM2008/GECO and XGM2019e_2159. The development of EGM2008/GECO included DNSC07GRA data (the predecessor of DNSC08GRA) over the SCS (Pavlis et al., 2012), where no Jason or CryoSat-2 data were included. Conversely, DTU13GRA was applied to develop XGM2019e_2159 (Zingerle et al., 2019), and 3 years (2010-2013) of CryoSat-2 data and 1 year (2012-2013) of Jason-1 data were included in DTU13GRA. As a result, DTU13GRA has better quality than DNSC07GRA, when compared with independent marine gravity data (Andersen et al., 2013). DTU17GRA is an updated version of DTU13GRA, which has better accuracy than DTU13GRA (Andersen \& Knudsen, 2019). Moreover, DTU13GRA is closer to DTU17GRA compared to DNSC07GRA, when validated against independent gravity data. Thus, XGM2019e_2159 has a better fit with DTU17GRA data than EGM2008/GECO because of the use of DTU13GRA data in the model development. 

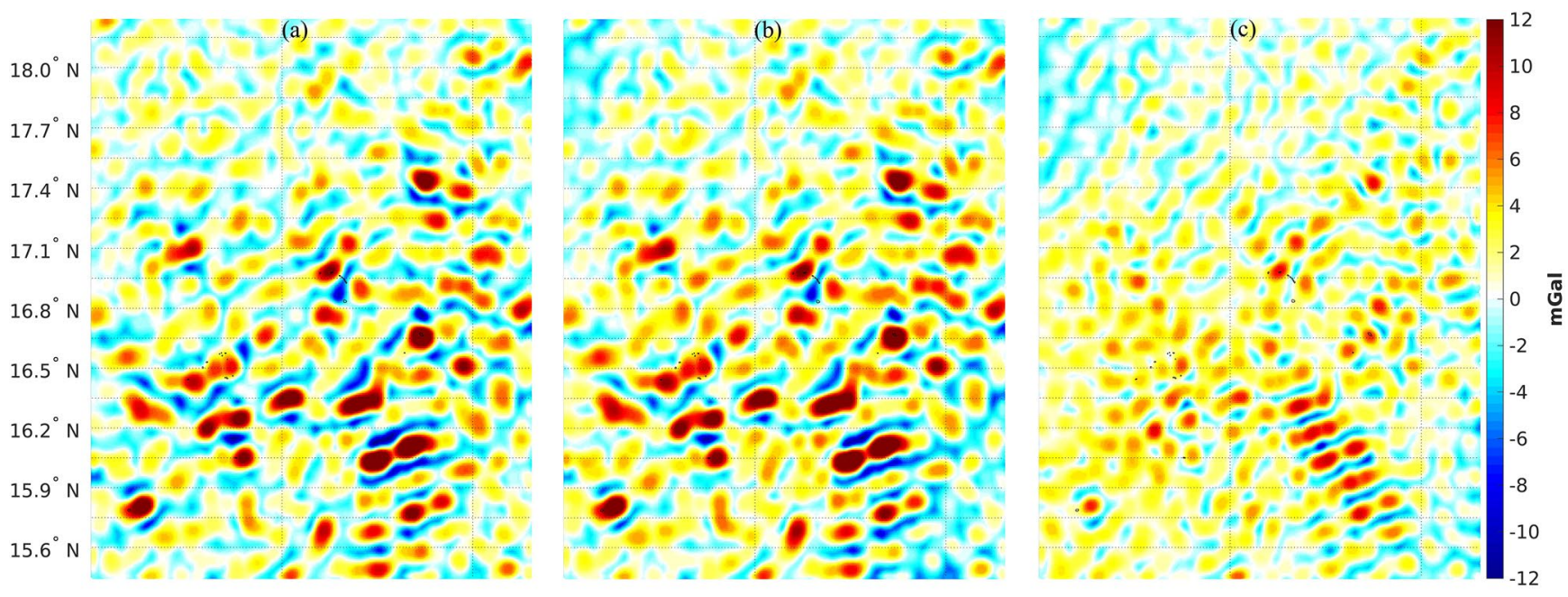

$111.0^{\circ} \mathrm{E} \quad 111.5^{\circ} \mathrm{E} \quad 112.0^{\circ} \mathrm{E} \quad 112.5^{\circ} \mathrm{E} \quad 113.0^{\circ} \mathrm{E} \quad 111.0^{\circ} \mathrm{E} \quad 111.5^{\circ} \mathrm{E} \quad 112.0^{\circ} \mathrm{E} \quad 112.5^{\circ} \mathrm{E} \quad 113.0^{\circ} \mathrm{E} 111.0^{\circ} \mathrm{E} \quad 111.5^{\circ} \mathrm{E} \quad 112.0^{\circ} \mathrm{E} \quad 112.5^{\circ} \mathrm{E} \quad 113.0^{\circ} \mathrm{E}$

Figure 2. Comparison of DTU17GRA-derived gravity anomalies and those synthesized from (a) EGM2008, (b) GECO, (c) XGM2019e_2159 up to degree 2190.

\subsection{Airborne Gravimetric Data}

The First Geodetic Surveying Brigade of the Ministry of Natural Resources of China implemented an airborne gravimetric survey over the Paracel Islands in 2018. This survey was conducted using a GT-2A gravimeter (e.g., Olsen, 2010), and consisted of 87 flights spanning $270 \mathrm{~km}$ in the east-west direction and $\sim 325 \mathrm{~km}$ in the north-south direction (see Figure 3). The traverse lines were north-south oriented with a mean resolution of $\sim 1.7 \mathrm{~km}$, and the tie lines were east-west oriented with an average spacing of $\sim 6 \mathrm{~km}$. The flight heights of this survey changed from 739 to $847 \mathrm{~m}$ above the mean sea level.

Gravity data are computed by removing airplane accelerations from the inertial data. Then, the Eötvös effects are corrected, and the off-level corrections are applied. The gravity disturbances are derived by subtracting the normal gravity values from the original gravity data, and a low-pass filter with a $0.01 \mathrm{~Hz}$ cut-off frequency is applied to reduce high-frequency noise. The mean spatial resolution of the airborne gravity data after filtering is $\sim 3 \mathrm{~km}$. The geodetic coordinates of airborne data are referenced to the GRS80 reference ellipsoid and the China Geodetic Coordinate System 2000 (CGCS, 2000). The SD of variations at seven repeat lines is $1.44 \mathrm{mGal}$; while the $\mathrm{SD}$ of differences at the crossovers of tie and transverse lines is 1.54 $\mathrm{mGal}$, which is marginally larger than the SD value at the repeat lines. These statistics are in accordance with the estimated accuracy of airborne gravity data in the High Altitude and Long Range Research Aircraft (GEOHALO) mission, where the errors at crossover points were estimated as $1.4 \mathrm{mGal}$ (Lu et al., 2017). Figure 3a shows the surveyed airborne gravity disturbances along the flight lines, and this airborne survey includes $\sim 1854900$ point-wise data, which range from -57.6 to $72.1 \mathrm{mGal}$, with a mean (SD) value of -9.5 (21.3) $\mathrm{mGal}$. The airborne data are used as another input data set for local gravity field modeling. A precision of $2 \mathrm{mGal}$ is assumed for the airborne data, and the final accuracy is estimated using the MCVCE.

We compare the observed airborne gravity disturbances with the quantities computed from different global gravity field models, see Figure 4, where GGM-derived gravity disturbances up to degree 2190 are computed at the point-wise airborne data locations. We see that XGM2019e_2159 reduces the discrepancies against the airborne data compared to EGM2008/

Table 1

Statistics of Differences Between DTU17GRA-Derived Gravity Anomalies and Those Synthesized From Different GGMs up to Degree 2190 (Units: $\mathrm{mGal}$ )

\begin{tabular}{lrccc}
\hline & Max & Min & Mean & SD \\
\hline EGM2008 & 20.62 & -13.70 & -0.03 & 3.09 \\
GECO & 21.38 & -12.70 & -0.31 & 3.18 \\
XGM2019e_2159 & 9.59 & -11.01 & -0.34 & 2.08 \\
\hline
\end{tabular}
GECO, and the SD of the misfits is $~ 3.3 \mathrm{mGal}$ with XGM2019e_2159; this value increases to $4.3 \mathrm{mGal}$ when EGM2008/GECO is evaluated, see the statistics in Table 2. These results are in line with those derived from the comparison of GGMs with the DTU17GRA data. During the development of DNSC07GRA that was used in computing EGM2008, limited amount of altimetry data were available, and there were data gaps near coasts and islands. This inevitably diminished the quality of altimetric gravity data used to compute EGM2008. Thus, the better fit of XGM2019e_2159 with 

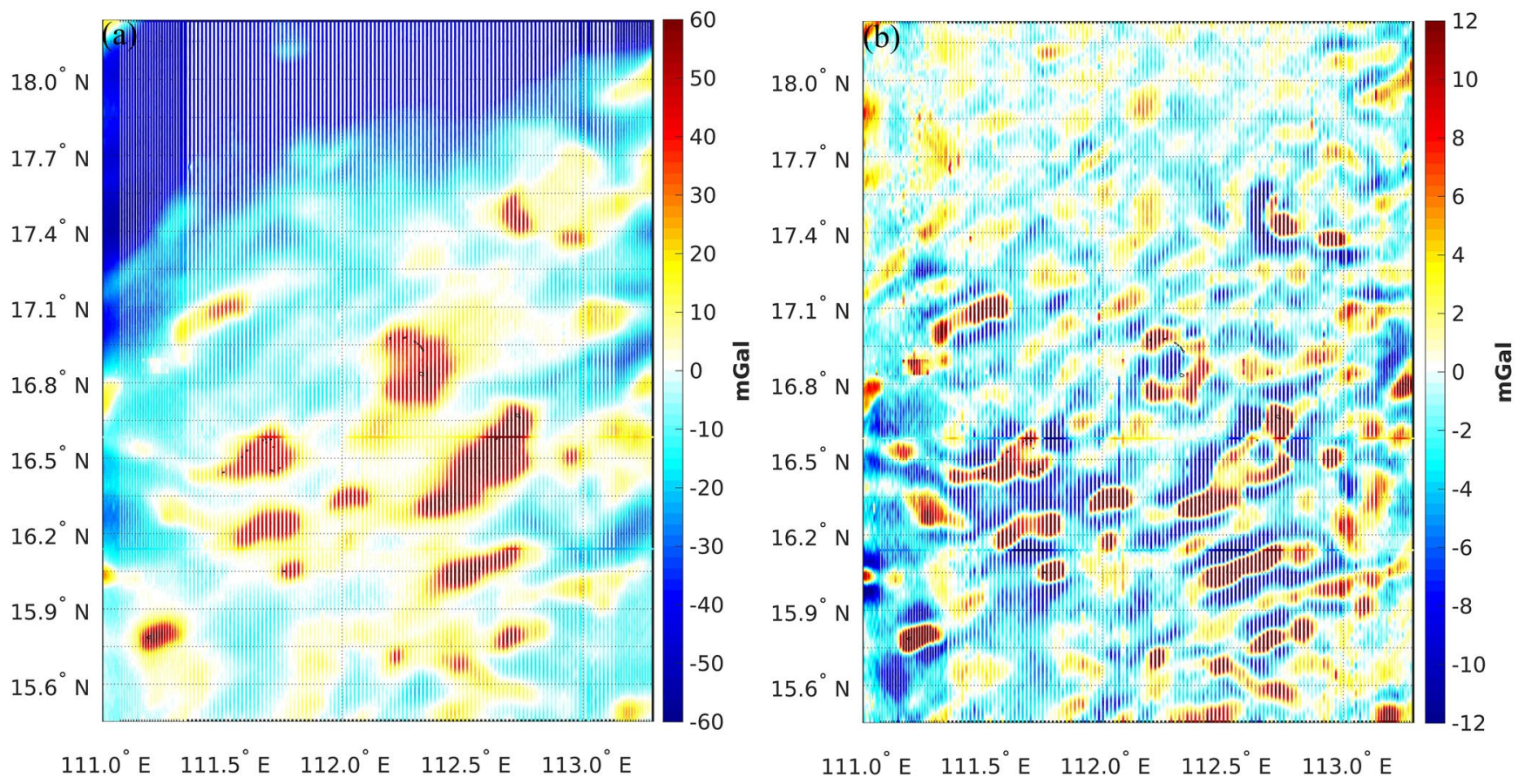

Figure 3. Surveyed airborne gravity disturbances along the flight lines (a) and the differences between observed gravity disturbances and those synthesized from EGM2008 up to degree 2190 (b).

the airborne data is largely attributed to the use of updated altimetric gravity data (i.e., DTU13GRA). We observe that prominent differences between the values computed from a GGM and the airborne data are concentrated around the Amphitrite and Crescent Groups, which is attributable to the deteriorated quality of altimetric gravity data used in the GGM's development near island areas.

It is notable that the ring effects occur when we compare the airborne gravity data and the values derived from a GGM. This may be largely attributed to the errors in a GGM, since no prominent ring effects are observed when the airborne data is compared with the DTU17GRA model, see Figure 4d. We compare the DTU17GRA model with the airborne data by using the spline interpolation in the altimetric grid to the location of the airborne observations. It is noteworthy that we did not downward continue the airborne data to the earth surface, and the airborne data at the flight altitude and the values derived from DTU17GRA model on the surface are directly compared. In comparison to the results derived from these GGMs, the DTU17GRA model shows a better fit with the airborne data, especially over coast/island areas, and the SD of the misfits decreases to $2.9 \mathrm{mGal}$. This is mainly attributed to the use of more high-quality data in DTU17GRA, for example, the recently released altimeter data (one year (2016-2017) of SARAL/AltiKa) and more CryoSat-2 data (from 2014-2017) that were not used in computing DTU13GRA or older versions. These results are in line with the ones derived when different altimetric gravity models were compared with the airborne data over the north Greenland and the marine gravity data in the northwest Atlantic Ocean, where DTU17GRA showed improved accuracy compared to older versions.

\subsection{Altimeter-Derived Geometric Quasi-Geoid Heights}

The altimeter-derived data, which are extracted from the radar altimeter database system (RADS; Scharroo et al., 2013), are used to compare with different global/regional gravity field models (Lieb et al., 2016; Wu et al., 2019). The comparisons with the altimeter-derived data may provide the information for the qualities of different quasi-geoid models over oceans, even in regions close to coast (Wu et al., 2019). In this study area, the ability to discriminate the qualities of different gravimetric quasi-geoid models by using the recently released altimeter-derived data is investigated; and this provides an initial evidence if the combination of local airborne and altimetric gravity data improves the local gravity field. 

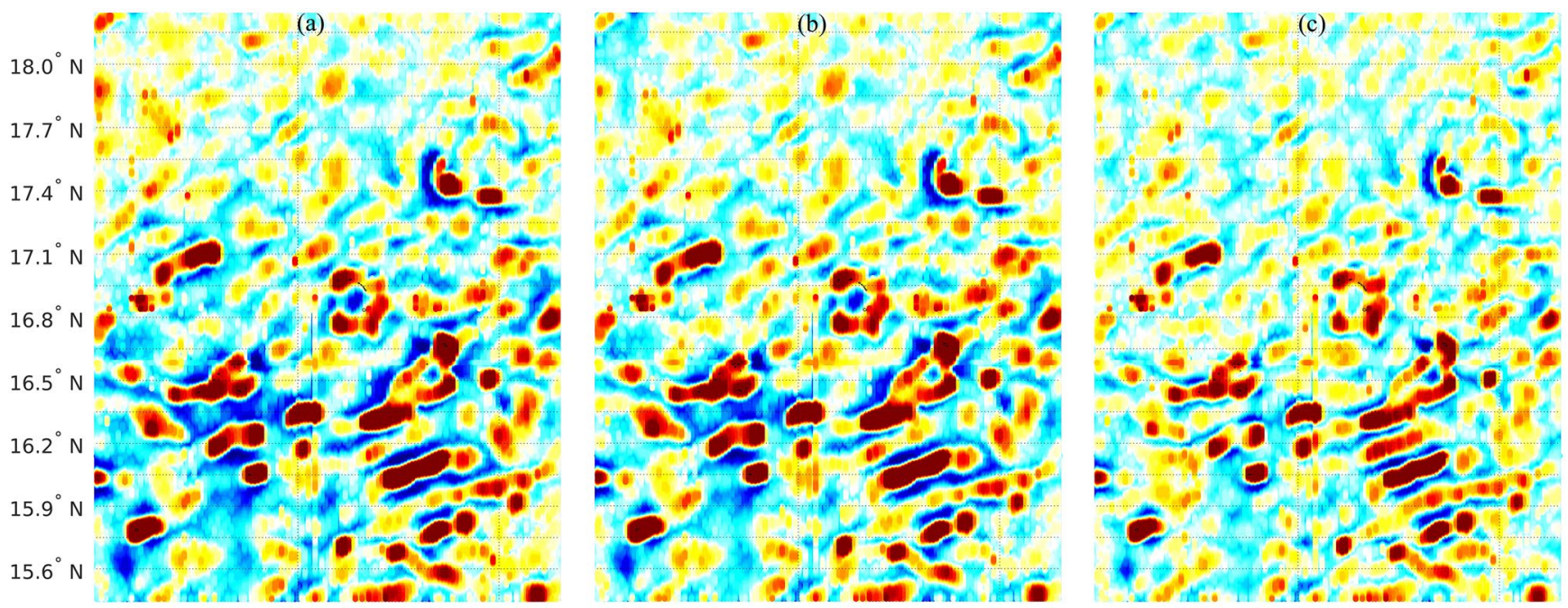

$111.0^{\circ} \mathrm{E} \quad 111.5^{\circ} \mathrm{E} \quad 112.0^{\circ} \mathrm{E} \quad 112.5^{\circ} \mathrm{E} \quad 113.0^{\circ} \mathrm{E} 111.0^{\circ} \mathrm{E} \quad 111.5^{\circ} \mathrm{E} \quad 112.0^{\circ} \mathrm{E} \quad 112.5^{\circ} \mathrm{E} \quad 113.0^{\circ} \mathrm{E} 111.0^{\circ} \mathrm{E} \quad 111.5^{\circ} \mathrm{E} \quad 112.0^{\circ} \mathrm{E} \quad 112.5^{\circ} \mathrm{E} \quad 113.0^{\circ} \mathrm{E}$

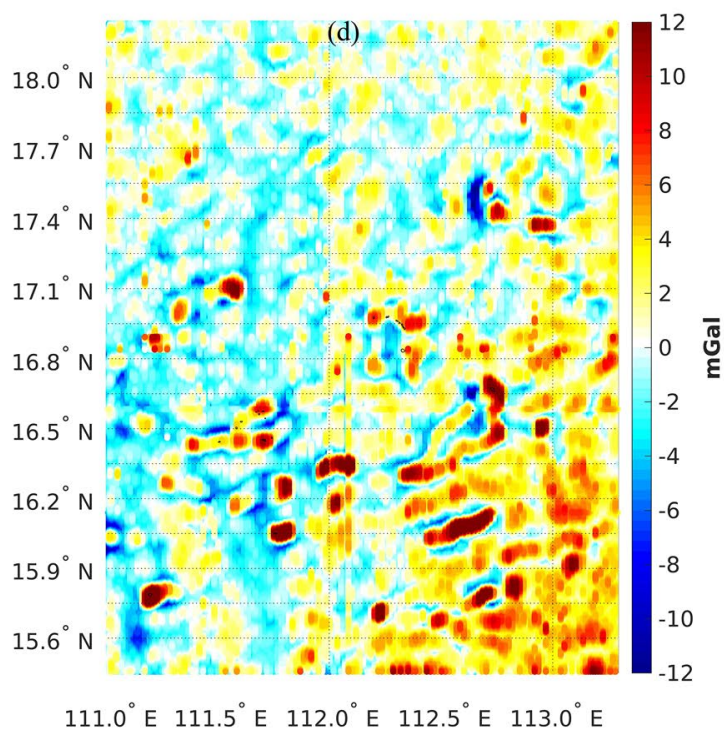

Figure 4. Comparison of observed airborne gravity disturbances and those derived from (a) EGM2008, (b) GECO, (c) XGM2019e_2159, and (d) DTU17GRA.

As the computation of the DTU17GRA model was also based on the altimeter data from the RADS, we only use the data that have not been utilized in deriving DTU17GRA. These data include more than two years (cycles 500-537 and 600-644 from July 2017 to October 2019) of the Jason-2 geodetic mission data (note: Jason-2 data were not included in DTU17GRA), approximately two and a half years (cycles 52-76 from January 2018 to June 2020) of the SARAL drifting phase data, and almost two and a half years (cycles 101-132 from January 2018 to June 2020) of

Table 2

Statistics Relating to Differences Between Surveyed Airborne Gravity Disturbances and Those Derived From Different Global Gravity Field Models (Units: $m G a l$ )

\begin{tabular}{lcccc}
\hline & Max & Min & Mean & SD \\
\hline EGM2008 & 36.09 & -18.23 & -0.93 & 4.28 \\
GECO & 37.02 & -17.19 & -0.63 & 4.22 \\
XGM2019e_2159 & 29.92 & -16.38 & -0.58 & 3.34 \\
DTU17GRA & 22.87 & -14.77 & -0.52 & 2.90 \\
\hline
\end{tabular}
the Cryosat-2 data (low resolution mode). Using these data ensures that comparisons with these altimeter data will be independent of the data source used to derive the local quasi-geoid.

A robust data screening process was employed to ensure the quality of $1 \mathrm{~Hz}$ observations near coastal zones and open seas. A modified Brown retracker (Brown, 1977) was used to process the altimetry waveforms in the RADS. In the $1 \mathrm{~Hz}$ data derivation, the SD of disparities between the derived $1 \mathrm{~Hz}$ observation and original data $(20 \mathrm{~Hz}$ for Jason-2/CryoSat-2, and $40 \mathrm{~Hz}$ for SARAL) offered an estimate of the error for a $1 \mathrm{~Hz}$ 
observation. In the study area, the maximum/minimum of estimated errors for the altimeter-derived data was $8 / 1.2 \mathrm{~cm}$, respectively, with a mean magnitude of $4.4 \mathrm{~cm}$.

The quasi-geoid signals synthesized from a GGM up to d/o 1080 (this is in line with the content we remove from a GGM in local gravity field modeling, and the truncation of d/o of a GGM is seen in Section 3.1.1) and the dynamic topography signals from the EGM2008 MDT (also known as the dynamic ocean topography (DOT)) (d/o 180), are removed from the sea surface heights to determine the residual quasi-geoid heights. The reason we chose EGM2008 MDT to remove dynamic topography signals is twofold. First, we mainly model the local gravity field at the medium- and shorter wavelengths ( $<20 \mathrm{~km}$, corresponds to d/o that higher than 1080). The commonly used MDTs have relatively low resolutions and mainly reflect the spectral contents at longer wavelengths, and the choice of MDT may have less impact on the comparison results. Moreover, EGM2008 is chosen as the one of the reference models to remove the long-wavelength quasi-geoid signals in altimetry data preprocessing. To ensure the spectral consistency in data preprocessing, we use EGM2008 DOT to remove dynamic topography signals. For the other two GGMs, we use the same MDT model to keep consistent with EGM2008.

After that, the residual terrain model (RTM) effects (Forsberg, 1984), though they are quite small, are removed. Then, the crossover adjustment, outlier detection, and filtering procedure are used to process the altimeter-derived data; detailed information is provided in Wu et al. (2019). We test the performances of three representative high-degree GGMs in quasi-geoid/MDT determination, whereby three sets of altimeter-derived geometric quasi-geoid heights are estimated.

\section{Results and Discussions}

\subsection{Local Gravity Field Recovery}

\subsubsection{Gravimetric Quasi-Geoid Computation}

We model the local quasi-geoid based on the remove-compute-restore (RCR) methodology (e.g., Featherstone et al., 2018; Omang \& Forsberg, 2000), and the residual terrain model is used to smooth the local gravity field. The GGM- and RTM-components are removed from local gravimetric observations to compute the residuals, based on which the residual quasi-geoid is modeled. The details regarding how we compute the RTM corrections are seen in Wu, Zhou et al., 2017, Wu et al., 2019. The residual gravity field is parameterized with Poisson wavelets, the order of which is fixed at three (Panet et al., 2011). The computational region spans $15.5^{\circ} \mathrm{N}$ to $18.2^{\circ} \mathrm{N}$ latitude and $111.0^{\circ} \mathrm{E}$ to $113.3^{\circ} \mathrm{E}$ longitude, where Poisson wavelets are placed on a Fibonacci grid located $5 \mathrm{~km}$ beneath the topography. This grid is parallel to the topography, and the average distance between Poisson wavelets is chosen as $10 \mathrm{~km}$ to achieve a balance between data fitting and obtaining a smooth solution. Further details regarding the local gravity field modeling based on Poisson wavelets are provided in previous studies, including Klees et al. (2008), Wu, Luo et al., 2017 and Wu, Zhou et al., 2017. The spatial resolution of the modeled quasi-geoid is determined by the mean resolution of local gravity data. The airborne gravity data set has a mean resolution of $\sim 3 \mathrm{~km}$, which is much denser than the DTU17GAR data (the true resolution of this model is slightly better than $10 \mathrm{~km}$ ). Thus, we recover the quasi-geoid heights on a grid that covers the study area, with a spatial resolution of $\sim 3 \mathrm{~km}$, which corresponds to the mean resolution of airborne data.

The use of local gravity data, especially the airborne gravity data, is expected not only to enhance the short-wavelength signals beyond the maximal degree of a high-degree GGM (i.e., to reduce the omission error), but also to improve the regional gravity field at medium-wavelengths (i.e., to reduce the commission error). In this manner, we truncate a GGM to a specific d/o instead of expanding it to the maximal d/o in quasi-geoid modeling. In order to choose the optimal truncated d/o, we consider three aspects. First, we ensure that the full-wavelength quasi-geoid signals can be recovered by using a GGM (truncated to a specific d/o) and local airborne and altimetric gravity data inside this study area, and no edge effects occur in the modeled quasi-geoid/MDT. Second, we try to reduce the commission error from a GGM as much as possible, where we study the error degree variances, offering a measure of commission error of this model. Finally, the qualities of MDTs computed from a GGM truncated to different d/o are assessed, where we use an independent ocean data set, providing an external assessment. 
We use the recently released XGM2019e_2159 as an example, where only the airborne gravity data are used for local gravity field modeling. We start the truncation of $d / o$ at 360, which is then increased with a step of 180, and we finally stop at the maximal expansion d/o. The details of numerical results are seen in Appendix A, where we find that the truncation of a GGM to d/o 1080 may be a proper choice, which reaches a compromise among these three aspects. To keep consistent with XGM2019e_2159, EGM2008/GECO is also truncated to d/o 1080 for local gravity field modeling.

As we finally truncate the GGMs to d/o 1080, the gravity anomalies/disturbances that are synthesized from a GGM up to d/o 1080 and the corresponding RTM corrections are removed from the DTU17GRA-derived gravity anomalies and airborne gravity disturbances to compute the residuals, and then the residual quasi-geoid models are computed. We compute three solutions for each GGM, the first solution is determined by using only the DTU17GRA-derived gravity anomalies, and the second one is modeled with the airborne gravity disturbances alone. The third solution is calculated by combining the DTU17GRA- and airborne-derived gravity data, where the surface altimetric gravity anomalies and airborne gravity disturbances at the flight altitude are directly combined, and no downward continuation is used (Wu, Zhou et al., 2017).

For local gravity field modeling, we first assume a priori accuracy for each observation group; and then the variance factors of different observation groups are estimated from MCVCE (Koch \& Kusche, 2002; Kusche, 2003), which are iteratively computed unit all the variance factors are convergent (Klees et al., 2008). The variance factor determines the relative weight of each observation group, playing a key role in data combination (Lieb et al., 2016). The square root of the variance factors, that is, the scale factors, are regarded as the posterior accuracies of different groups. For the solution using XGM2019e_2159 as the reference model, the estimated scale factor of the airborne data is $~ 1.59 \mathrm{mGal}$ when the DTU17GRA- and airborne-derived gravity data are merged. This value is slightly larger than that derived from the repeat flight lines $(\sim 1.44$ $\mathrm{mGal})$, but coincides with the SD of differences at the crossovers ( $\sim 1.54 \mathrm{mGal})$. In contrast, the estimated value of the altimetry-derived gravity data is $\sim 2.32 \mathrm{mGal}$, which may be a bit of optimistic considering that the accuracy of the DTU17GRA model was $\sim 2.51 \mathrm{mGal}$ when compared with the marine gravity data from the NGA (Andersen \& Knudsen, 2019).

Figure 5 shows the residual quasi-geoid signals modeled from different data, and Table 3 presents the statistics. The residual quasi-geoid heights solely computed from the DTU17GRA data based on various reference models have similar structures (see the figures on the left side of Figure 5), ranging from approximately -10.9 to $15.7 \mathrm{~cm}$, with a SD of $\sim 2.4 \mathrm{~cm}$, see Table 3 . In contrast, these values range from -12.8 to $23.5 \mathrm{~cm}$ (with a SD of $\sim 3.6 \mathrm{~cm}$ ) when the airborne gravity data is applied for quasi-geoid modeling. The quasi-geoid signals computed from the airborne data display more significant patterns than those computed from the altimetric gravity data (see the figures on the middle side of Figure 5), especially over the regions around the Amphitrite and Crescent Groups. This indicates that the airborne data may contain additional signals that cannot be resolved from the altimetry data alone. The DTU17GRA data focuses on enhancing signals at a wavelength of approximately 10-15 km (Andersen \& Knudsen, 2019); whereas, the airborne survey maps the local gravity field at a denser resolution $(\sim 3 \mathrm{~km})$, which can contribute to quasi-geoid modeling at shorter wavelengths $(<10 \mathrm{~km})$ than the satellite altimetry data. Moreover, the airborne gravimetry does not experience issues like waveform contamination near coasts and islands, provides data over land/island and ocean with consistent precision, which is possible to overcome the drawbacks of satellite altimetry in regions close to land/island.

The residual quasi-geoids computed by the combination of DTU17GRA- and airborne-derived gravity data almost have consistent structures as the ones modeled from the airborne data alone, see the figures on the right side of Figure 5. The statistics in Table 3 also demonstrate that the solutions modeled solely from the airborne data closely agree with the ones derived by additionally combining the altimetric gravity data. This demonstrates that the airborne gravity data plays a dominant role in regional gravity field recovery at medium- and short-wavelengths over the study area, and the additional signals introduced from the altimetric gravity data may be marginal if the airborne data have been used for local refinement.

\subsubsection{Comparison With Altimeter Data}

The altimeter-derived geometric quasi-geoid heights are compared with gravity field models over oceanic areas. Figure 6 shows the comparison results, and the figures in the first column show the disparities 

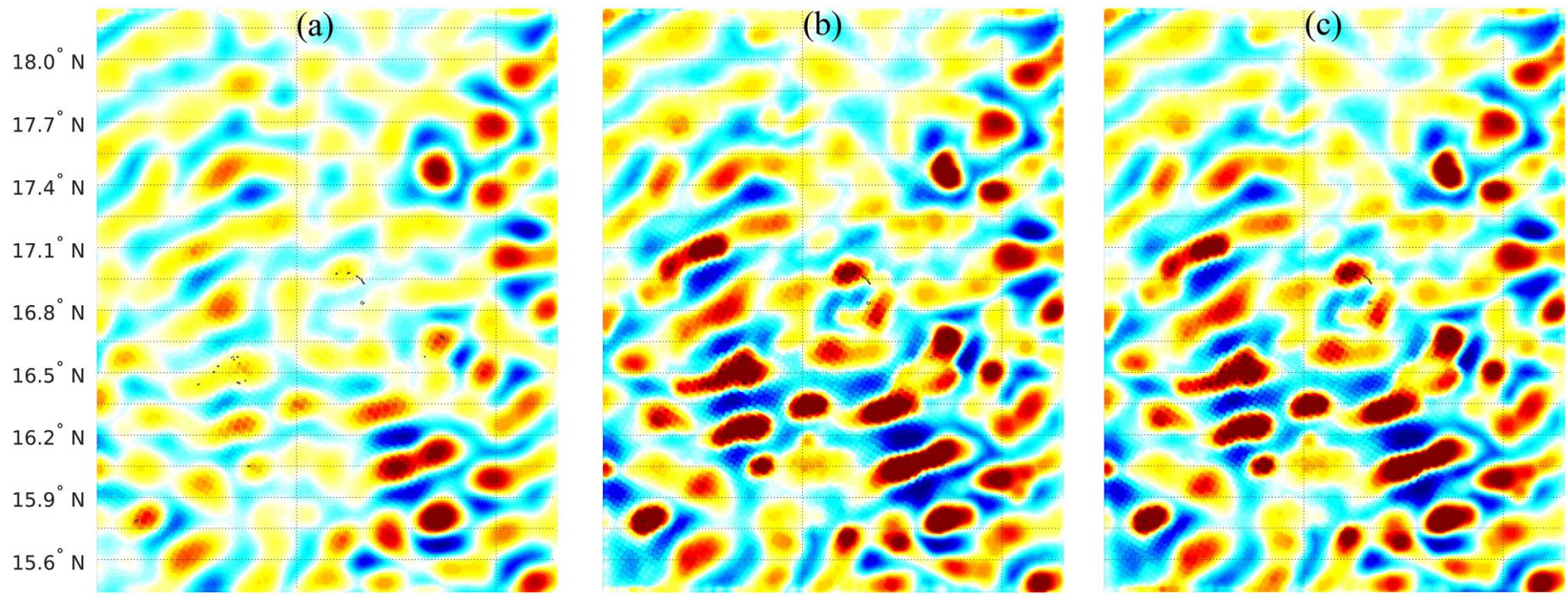

$111.0^{\circ} \mathrm{E} 111.5^{\circ} \mathrm{E} 112.0^{\circ} \mathrm{E} 112.5^{\circ} \mathrm{E} 113.0^{\circ} \mathrm{E}$
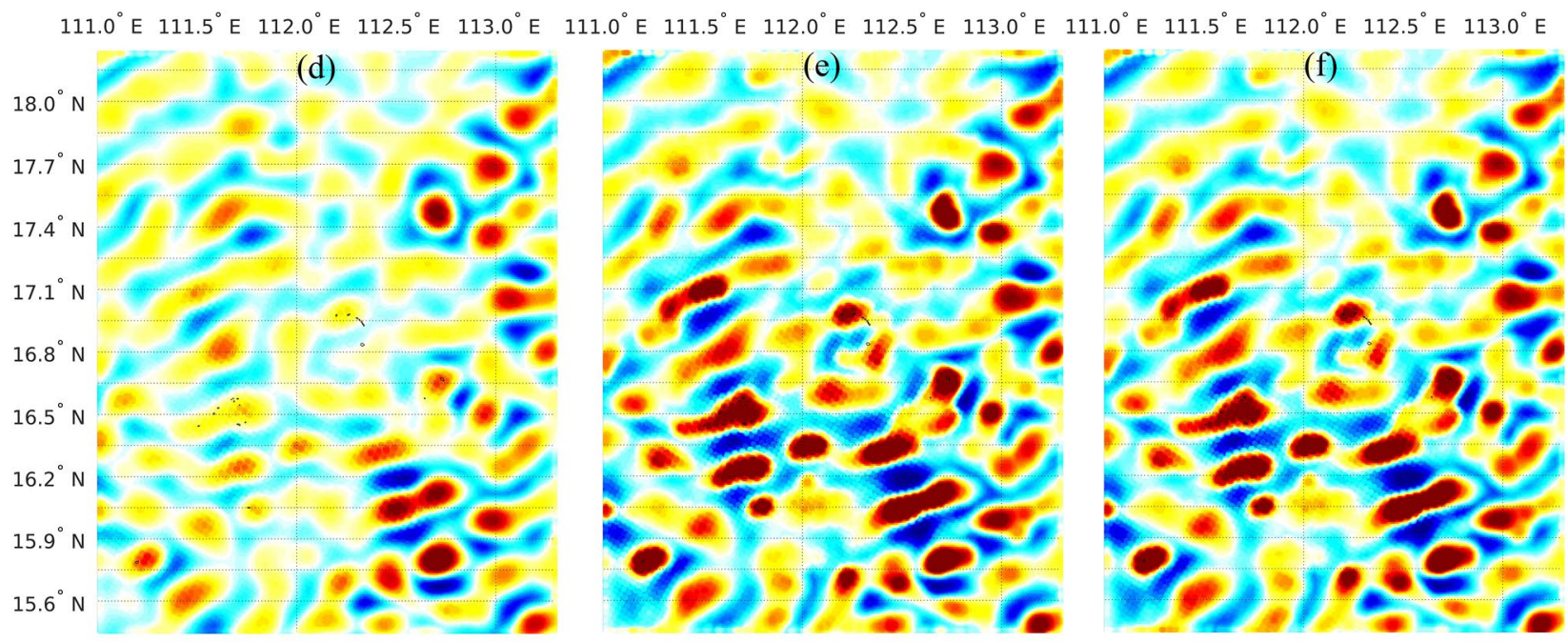

$111.0^{\circ} \mathrm{E} 111.5^{\circ} \mathrm{E} 112.0^{\circ} \mathrm{E} 112.5^{\circ} \mathrm{E} 113.0^{\circ} \mathrm{E}$
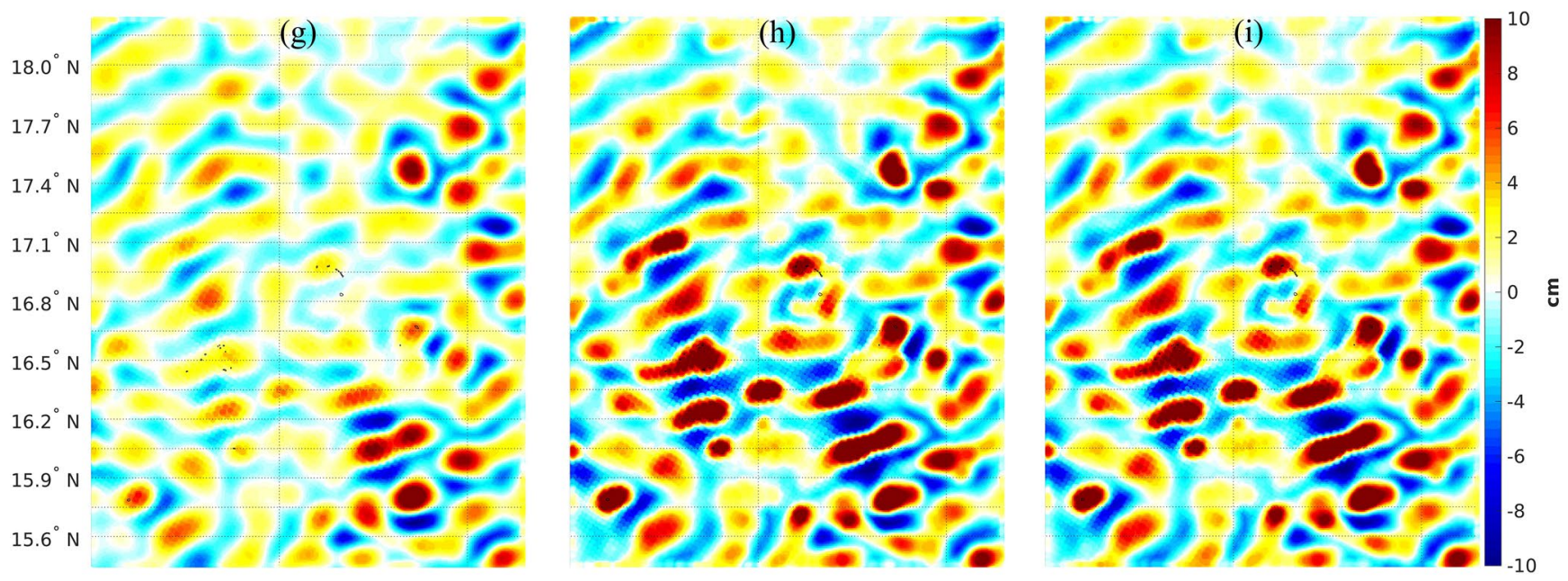

$111.0^{\circ} \mathrm{E} \quad 111.5^{\circ} \mathrm{E} \quad 112.0^{\circ} \mathrm{E} \quad 112.5^{\circ} \mathrm{E} \quad 113.0^{\circ} \mathrm{E} \quad 111.0^{\circ} \mathrm{E} \quad 111.5^{\circ} \mathrm{E} \quad 112.0^{\circ} \mathrm{E} \quad 112.5^{\circ} \mathrm{E} \quad 113.0^{\circ} \mathrm{E} \quad 111.0^{\circ} \mathrm{E} \quad 111.5^{\circ} \mathrm{E} \quad 112.0^{\circ} \mathrm{E} \quad 112.5^{\circ} \mathrm{E} \quad 113.0^{\circ} \mathrm{E}$

Figure 5. Residual quasi-geoid signals computed from different gravity data based on various high-degree global geopotential models (GGMs). The top, middle, and bottom panels represent the results when EGM2008, GECO, and XGM2019e_2159 are used as reference models, respectively. The figures on the left hand side (a, d, and g) show the results when only altimetric gravity data is used, the figures on the middle side (b, e, and h) display the results derived from airborne gravity data alone, and the figures on the right hand side (c, f, and i) demonstrate the results computed by merging altimetry- and airborne-derived gravity data. 
Table 3

Statistics on the Residual Quasi-Geoid Signals Computed From Different Gravity Data Based on Various Reference Models (Units: $\mathrm{cm}$ ) (Altimery: Altimetric Gravity Data; Airborne: Airborne Gravity Data)

\begin{tabular}{lccccc}
\hline & & Max & Min & Mean & SD \\
\hline \multirow{2}{*}{ EGM2008 } & Altimetry & 15.4 & -10.6 & 0.0 & 2.4 \\
& Airborne & 23.4 & -12.8 & -0.1 & 3.6 \\
& Altimetry + Airborne & 23.6 & -12.9 & -0.1 & 3.7 \\
GECO & Altimetry & 15.7 & -10.4 & 0.0 & 2.4 \\
& Airborne & 23.1 & -12.8 & -0.1 & 3.6 \\
& Altimetry + Airborne & 23.2 & -12.8 & -0.1 & 3.7 \\
XGM2019e_2159 & Altimetry & 15.4 & -10.9 & 0.0 & 2.4 \\
& Airborne & 23.5 & -12.3 & -0.1 & 3.5 \\
& Altimetry + Airborne & 23.7 & -12.6 & -0.1 & 3.6 \\
\hline
\end{tabular}

between different GGMs (note that the contents up to d/o 1080 are removed from a GGM, corresponding to what have been removed in the altimeter data) and the altimeter data. The misfits between a GGM and the altimeter data include the commission error of a GGM, the error in the altimeter data, and the signals contained in the altimeter data that are unresolved in a GGM. The misfits between XGM2019e_2159 and the altimeter data are smaller than those derived from EGM2008/GECO, where the maximum/minimum of inconsistencies derived from XGM2019e_2159 is $5.4 /-4.8 \mathrm{~cm}$, with a SD of $1.2 \mathrm{~cm}$ (Table 4$)$. In contrast, the maximum/ minimum of the misfits changes to $6.8 /-6.4 \mathrm{~cm}(7.9 /-6.1 \mathrm{~cm})$ when EGM2008 (GECO) is compared, and the SD value increases to $1.4 \mathrm{~cm}$ $(1.5 \mathrm{~cm})$. These results indicate that the commission errors of different GGMs may be not identical, despite these models expand to the same d/o.

By combining the DTU17GRA-derived gravity data, the differences between the associated quasi-geoid models and the altimeter-derived quasi-geoid heights attenuate in the southern and eastern Paracel Islands. An example of this is in the areas around $16.1^{\circ} \mathrm{N}, 112.6^{\circ} \mathrm{E}$, see the figures in the second column of Figure 6. Table 4 shows that the magnitude of the maximum/minimum of the misfits between the quasi-geoid modeled by combining the DTU17GRA data alone and the altimeter data is reduced by $1.8 / 1.1 \mathrm{~cm}(2.0 / 0.8 \mathrm{~cm})$, when EGM2008 (GECO) is used as the reference model, compared to the maximum/minimum value derived from the comparison with EGM2008 (GECO).

The combination of the airborne data further reduces the discrepancies between the associated quasi-geoids and the altimeter-derived quasi-geoid heights, compared to the models computed by using the DTU17GRA data alone. This is particularly the case for regions close to islands, see the figures in the last two columns of Figure 6. The SD of misfits between the quasi-geoids modeled by combining the airborne gravity data and the altimeter data are 1.0, 1.1, and $0.9 \mathrm{~cm}$ when EGM2008, GECO, and XGM2019e_2159 are used as the reference models, respectively. This is represented reductions of approximately 4 , 4, and $3 \mathrm{~mm}$, compared to the results derived from the comparisons with EGM2008, GECO, and XGM2019e_2159, respectively. By merging the airborne data alone, the maximums of the misfits against the altimeter data change to 4.8, 4.3, and $3.6 \mathrm{~cm}$ when EGM2008, GECO, and XGM2019e_2159 are used as the reference models, respectively. This constitutes a reduction of approximately $1.8-3.6 \mathrm{~cm}$, compared to the results derived when the GGMs are compared with the altimeter data. The combination of the airborne data also improves the fit with the altimeter data compared to the result computed only with the DTU17GRA data, by a magnitude of $\sim 2 \mathrm{~mm}$ when the SD values of the misfits are compared. The comparison result derived from the model computed with the airborne gravity data alone closely agrees with the one computed by additionally combining the altimetric gravity data.

\subsection{Geodetic MDT Determination}

The geodetic MDT is computed by removing the geoid from the MSS, where DTU18MSS is used as the MSS model. DTU18MSS (1-arcmin grid spacing) was determined by combining the synthetic aperture radar (SAR) data from Sentinel-3A over coastal zones and reprocessing Cryosat-2 data over the Arctic and Antarctic; this differs from the previous version (i.e., DTU15MSS) (Andersen, Knudsen, et al., 2018). Moreover, the quasi-geoid closely agrees with the geoid over oceans, and the separation of geoid and quasi-geoid is typically within submillimeter level (Tenzer \& Foroughi, 2018). We use the quasi-geoid instead of geoid for MDT modeling over the study area. To compute the MDT models, a MSS grid spanning the study area is initially extracted from the DTU18MSS model, and the quasi-geoid heights obtained from global/regional gravity field models are synthesized on this grid. Then, local MDTs are directly computed by subtracting the quasi-geoid heights from DTU18MSS.

Figure 7 displays the raw MDTs derived from different global/regional quasi-geoid models; the direct applications of a high-degree GGM in MDT determination cause significant oscillations around the Amphitrite and Crescent Groups, as shown in the figures in the first column of Figure 7. The commission errors of a 

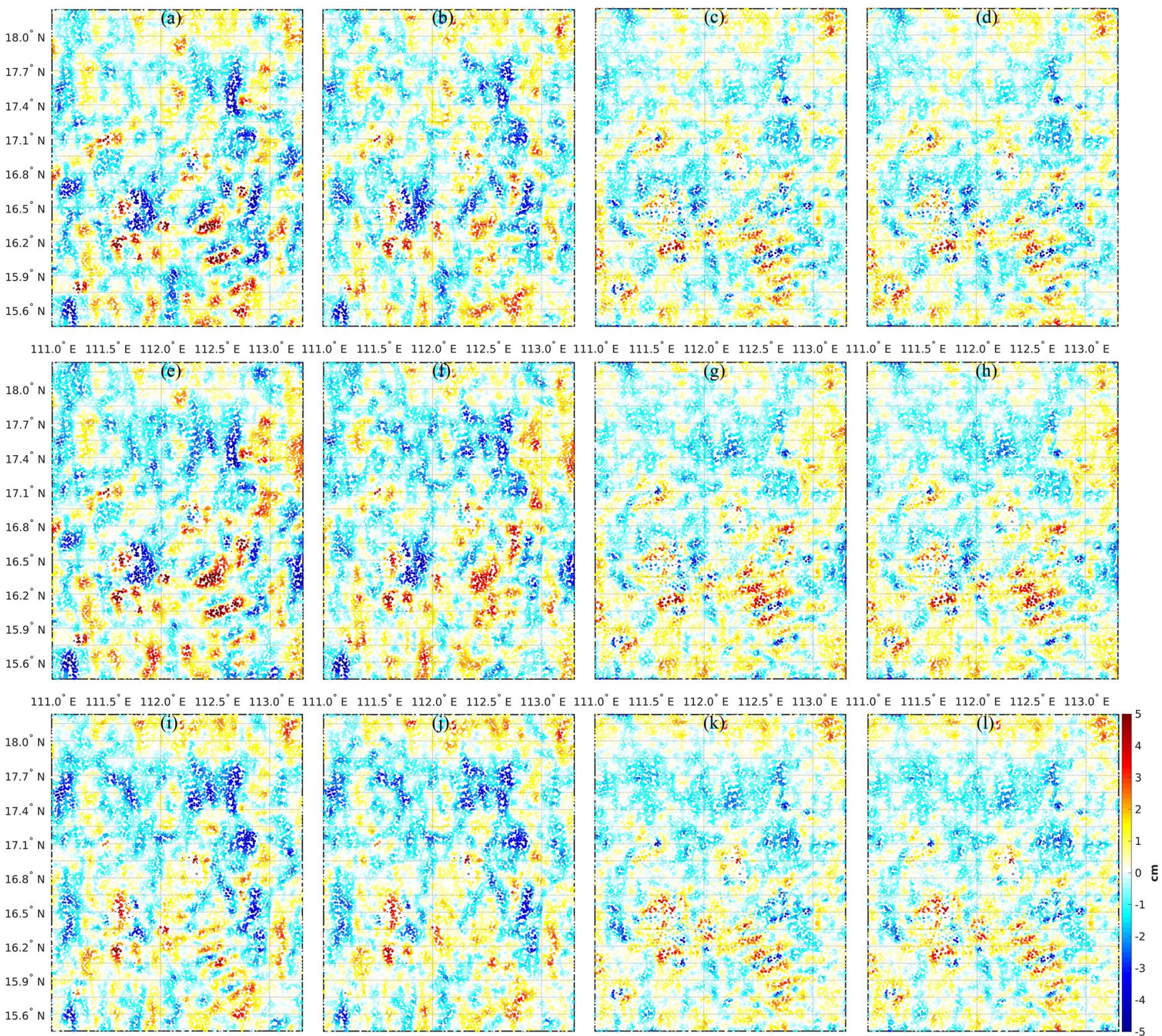

$111.0^{\circ} \mathrm{E} \quad 111.5^{\circ} \mathrm{E} \quad 112.0^{\circ} \mathrm{E} \quad 112.5^{\circ} \mathrm{E} \quad 113.0^{\circ} \mathrm{E} \quad 111.0^{\circ} \mathrm{E} \quad 111.5^{\circ} \mathrm{E} \quad 112.0^{\circ} \mathrm{E} \quad 112.5^{\circ} \mathrm{E} \quad 113.0^{\circ} \mathrm{E} \quad 111.0^{\circ} \mathrm{E} \quad 111.5^{\circ} \mathrm{E} \quad 112.0^{\circ} \mathrm{E} \quad 112.5^{\circ} \mathrm{E} \quad 113.0^{\circ} \mathrm{E} \quad 111.0^{\circ} \mathrm{E} \quad 111.5^{\circ} \mathrm{E} \quad 112.0^{\circ} \mathrm{E} \quad 112.5^{\circ} \mathrm{E} \quad 113.0^{\circ} \mathrm{E}$

Figure 6. Comparisons of different quasi-geoid models computed from various reference models with altimeter data. The top, middle, and bottom panels represent the results when EGM2008, GECO, and XGM2019e_2159 are used as the reference models, respectively. The figures in the first column (a, e, and i) display the results when different global geopotential models (GGMs) are compared with altimeter data, the figures in the second column (b, $\mathrm{f}$, and $\mathrm{j}$ ) demonstrate the results when regional solutions computed by only combining DTU17GRA data are compared with altimeter data, the figures in the third column (c, g, and k) show the results when regional solutions computed by using airborne data alone are compared with altimeter data, and the figures in the last column ( $\mathrm{d}, \mathrm{h}$, and $\mathrm{l})$ manifest the results when the regional solutions computed by merging DTU17GRA and airborne data are compared with altimeter data.

high-degree GGM propagate into the associated MDT, leading to the errors up to a magnitude of several centimeters over oceanic area (Pavlis et al., 2012). Moreover, the spectral contents beyond the maximal degree of a GGM $(<10 \mathrm{~km})$ have not been resolved, generating high-frequency omission errors that also propagate into the associated MDT. This displays that the use of a high-degree GGM alone may be inadequate to recover high-accuracy MDT, especially over coastal/island areas. It is noticeable this is not only an issue for the selected GGMs in this study, but also for other existing high-degree models. By comparing the MDTs computed from different GGMs, we find that the MDT derived from XGM2019e_2159 demonstrates smaller oscillations than the one derived from EGM2008/GECO. This may be mainly due to the use of an updated 


\begin{tabular}{|c|c|c|c|c|c|}
\hline & Additional data & Max & Min & Mean & SD \\
\hline \multirow[t]{4}{*}{ EGM2008 } & - & 6.8 & -6.4 & -0.2 & 1.4 \\
\hline & Altimetry & 5.0 & -5.3 & -0.2 & 1.2 \\
\hline & Airborne & 4.8 & -5.9 & -0.1 & 1.0 \\
\hline & Altimetry + Airborne & 4.9 & -5.6 & -0.1 & 1.0 \\
\hline \multirow[t]{4}{*}{ GECO } & - & 7.9 & -6.1 & -0.2 & 1.5 \\
\hline & Altimetry & 5.9 & -5.3 & -0.1 & 1.3 \\
\hline & Airborne & 4.3 & -5.5 & -0.0 & 1.1 \\
\hline & Altimetry + Airborne & 4.4 & -5.4 & -0.0 & 1.1 \\
\hline \multirow[t]{4}{*}{ XGM2019e_2159 } & - & 5.4 & -4.8 & -0.2 & 1.2 \\
\hline & Altimetry & 4.9 & -4.7 & -0.2 & 1.1 \\
\hline & Airborne & 3.6 & -4.9 & -0.1 & 0.9 \\
\hline & Altimetry + Airborne & 3.6 & -4.7 & -0.1 & 0.9 \\
\hline
\end{tabular}

altimetric gravity model with improved accuracy (i.e., DTU13GRA) in XGM2019e_2159, compared to an older model (i.e., DNSC07GRA) used in EGM2008/GECO.

In contrast, smaller oscillations occur in the MDT computed by combining the altimetric gravity data alone, see the figures in the second column of Figure 7, compared to the MDT directly determined from a GGM. DTU17GRA was developed by improving the coastal gravity field, which enhances the short wavelengths of the marine gravity field (10-15 km). This model shows improved accuracy, when compared to the previous versions, for example, DTU13GRA/DNSC07GRA. The combination of DTU17GRA data may slightly improve the short-wavelength signals of local quasi-geoid; and consequently, improve the associated MDT, compared to the one directly derived from a GGM. However, the bubble-like errors are still prominent near island areas around the Amphitrite and Crescent Groups. This demonstrates that altimetry data alone may be insufficient for high-accuracy MDT recovery over island areas, owing to the limited accuracy and spatial resolution.

The combination of the airborne data dramatically reduces the oscillations in the associated MDT, see the figures in the last two columns of Figure 7. The MDT modeled by combining the airborne data exhibits much smoother structures than the one directly determined from a GGM and the model calculated by only combining the DTU17GRA data, where almost no prominent bubble-like errors are observed. The airborne survey does not suffer from waveform contamination near coasts and islands, and provides more accurate data than altimetry data over these regions. Moreover, the local airborne survey samples the local gravity field at a denser resolution $(\sim 3 \mathrm{~km})$ than the altimetry data, which introduces the additional short-wavelength signals that have not been resolved in the DTU17GRA model. As a result, the combination of airborne data further improves the local quasi-geoid and reduces the errors in associated MDT, compared to the one computed without airborne data. We also see that the MDT derived from the airborne data alone and the one by additionally combining the altimetric gravity data show almost consistent structures, owing to the dominant role that the airborne data played in local gravity field recovery over the study area.

We investigate the characteristics of different MDTs along two profiles, and the positions of these two profiles are seen in the black lines in Figure 7l. Figure 8 shows the behavior of MDTs along longitude $112.5^{\circ} \mathrm{E}$. The overall variations among different MDTs are greater near the south of $16.4^{\circ} \mathrm{N}$ than near the north of $16.4^{\circ} \mathrm{N}$, see Figure $8 \mathrm{a}, 8 \mathrm{~b}$, and $8 \mathrm{c}$. This coincides with the MDT properties in Figure 7, where substantial oscillations occur in the MDT computed without the airborne data in the southern Paracel Islands. The MDT modeled with the airborne gravity data alone closely agrees with the one modeled by combining the altimetry- and airborne-derived gravity data, where the mutual differences between these two MDTs are within $3 \mathrm{~mm}$. This indicates that if a high-resolution and high-quality airborne gravimetry was implemented, the discard of altimetric gravity data may have negligible effects on local MDT recovery with centimeter-level accuracy.

Whereas, the spike-like errors appear in the MDTs modeled without the airborne gravity data, which are extremely prominent when this profile passes through the Bombay Reef $\left(16.05^{\circ} \mathrm{N}, 16.15^{\circ} \mathrm{N}\right)$ and Bremen Bank $\left(16.3^{\circ} \mathrm{N}\right)$. The disparities between the MDT directly computed from EGM2008/GECO and one derived by combining the airborne data exceed $6 \mathrm{~cm}$ around the Bombay Reef. The MDTs computed from XGM2019e_2159 demonstrated smaller variations than those derived from EGM2008/GECO; however, the misfits among different MDTs are still prominent around the Bombay Reef and Bremen Bank. In these areas, the discrepancies between the MDT modeled with XGM2019e_2159 alone and that computed by combining the airborne data are larger than $3 \mathrm{~cm}$. The MDTs computed by merging the altimetric gravity data have lower oscillations than the models directly estimated from the high-degree GGMs; however, the misfits between these MDTs and the models computed by additionally combining the airborne data are evident around the Bombay Reef and Bremen Bank. For instance, near the Bombay Reef and Bremen Bank, these 

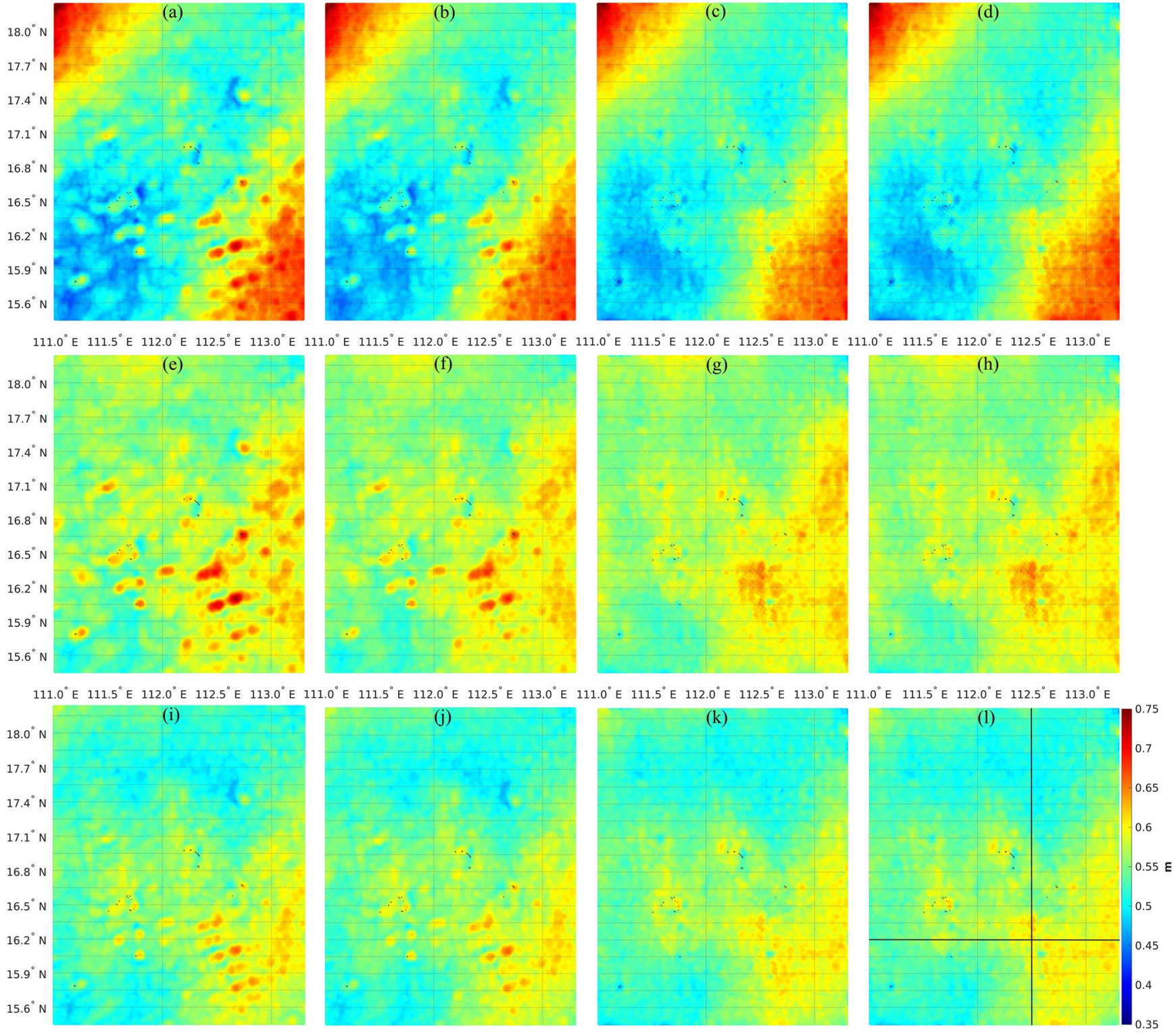

$111.0^{\circ} \mathrm{E} \quad 111.5^{\circ} \mathrm{E} \quad 112.0^{\circ} \mathrm{E} \quad 112.5^{\circ} \mathrm{E} \quad 113.0^{\circ} \mathrm{E} \quad 111.0^{\circ} \mathrm{E} \quad 111.5^{\circ} \mathrm{E} \quad 112.0^{\circ} \mathrm{E} \quad 112.5^{\circ} \mathrm{E} \quad 113.0^{\circ} \mathrm{E} \quad 111.0^{\circ} \mathrm{E} 111.5^{\circ} \mathrm{E} 112.0^{\circ} \mathrm{E} \quad 112.5^{\circ} \mathrm{E} \quad 113.0^{\circ} \mathrm{E} \quad 111.0^{\circ} \mathrm{E} \quad 111.5^{\circ} \mathrm{E} \quad 112.0^{\circ} \mathrm{E} \quad 112.5^{\circ} \mathrm{E} \quad 113.0^{\circ} \mathrm{E}$

Figure 7. Mean dynamic topographys (MDTs) computed from global/regional gravity field models. The top, middle, and bottom panels represent the MDTs computed when EGM2008, GECO, and XGM2019e_2159 are used as reference models, respectively. The figures in the first column (a, e, and i) show the MDTs directly computed with high-degree global geopotential models (GGMs) (up to the maximal d/o), the figures in the second column (b, f, and j) display the MDTs computed with the regional solutions modeled by only combining DTU17GRA data, the figures in the third column (c, g, and k) manifest the MDTs computed with the regional solutions derived by combining airborne gravity data alone, and the figures in the last column (d, h, and l) demonstrate the MDTs computed with the regional solutions modeled by merging DTU17GRA and airborne data. The black lines in (l) represent the positions of two profiles.

differences exceed $2 \mathrm{~cm}$ when XGM2019e_2159 is used as the reference model. In contrast, the MDTs modeled with the airborne data exhibit relatively smooth structures, where almost no apparent spikes appear.

In addition, we compare the MDTs computed from different reference models, where the solutions modeled by merging the altimetric and airborne gravity data are used. Moreover, a purely ocean model, namely Simple Ocean Data Assimilation, version 3 (SODA3) (Carton et al., 2018), is used for comparison. SODA3 was developed by ocean reanalysis with enhancements to model resolution, observation, and forcing data, in addition to active sea ice. SODA3 provides monthly data from 1980 to 2017 with a horizontal resolution of $0.25^{\circ}$. To extract the MDT signals from SODA3, we first compute the mean SODA MDT by averaging the monthly data from 1993 to 2017. After that, the SODA MDT is adjusted to 1993-2018 through the method 

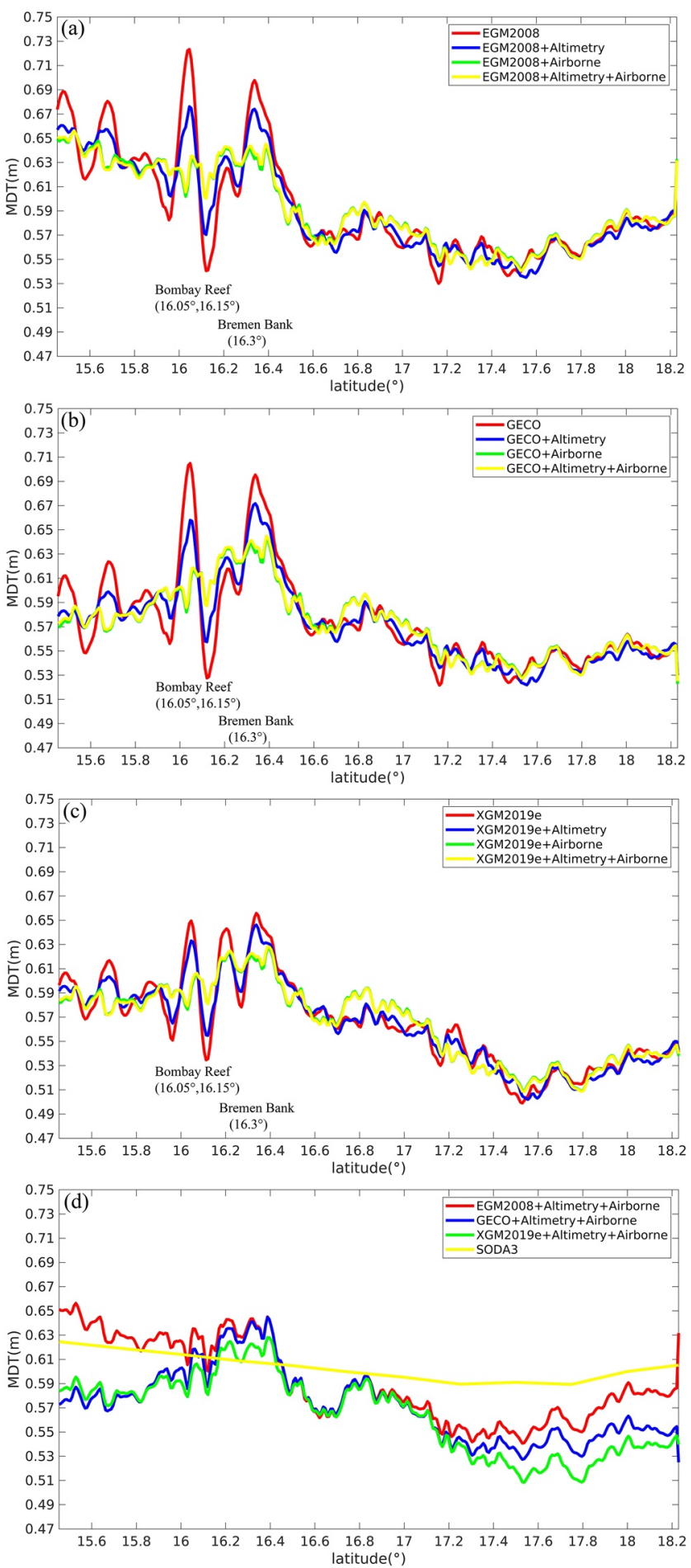

Figure 8. Profiles of different mean dynamic topographys (MDTs) along longitude $112.5^{\circ} \mathrm{E}$. suggested by Bingham and Haines (2006) by using the AVISO altimetric sea level anomaly (SLA) data (e.g., Rio et al., 2011); and this time period is in line with the local geodetic MDTs modeled with DTU18MSS.

Figure $8 \mathrm{~d}$ shows different MDTs along longitude $112.5^{\circ} \mathrm{E}$. Although a general decreasing trend is observed in all geodetic/ocean MDTs from south to north, the differences among these MDTs reach a magnitude larger than $5 \mathrm{~cm}$. The SODA MDT displays smoother patterns than these three geodetic MDTs, which is mainly due to its limited resolution ( $\sim 30 \mathrm{~km}$ ); and consequently, the short-wavelength contents that have the wavelengths shorter than $30 \mathrm{~km}$ cannot be recovered from this model. In contrast, the geodetic MDTs modeled from local gravity data have much higher resolutions, which contain more short-wavelength contents that cannot be resolved in this ocean model. Moreover, the inconsistencies among different geodetic MDTs reach a magnitude of several centimeters, which are particularly prominent at north of $16.1^{\circ} \mathrm{N}$ and south of $17.5^{\circ} \mathrm{N}$. This is mainly due to the inconsistencies among different GGMs at long-wavelength bands, which are attributed to the different modeling techniques and data sources that used in those models' development. For instance, GOCE data were not used in EGM2008; while, GECO and XGM2019e_2159 were computed by combining GOCE data. Moreover, the development of EGM2008/GECO included DNSC07GRA data; conversely, an updated model, that is, DTU13GRA, was used to develop XGM2019e_2159. Since we model the local quasi-geoids based on the RCR method, where the long-wavelength signals (>20 km, corresponding to d/o lower than 1080) are synthesized from a GGM; and consequently, the long-wavelength differences among different GGMs are manifested in the associated MDTs. We also notice that the MDTs derived from GECO and XGM2019e_2159 have better mutual agreement than that derived from EGM2008. This may be due to the combination of GOCE data in GECO/XGM2019e_2159, which substantially improved the global gravity field at the long-wavelength bands, that is, from degree 30 to 220 .

Figure 9 illustrates the behavior of MDTs along latitude $16.2^{\circ} \mathrm{N}$. Similar as the results shown in the profile along longitude $112.5^{\circ} \mathrm{E}$, the MDT modeled with airborne data alone agrees well with the one modeled by additionally combining the altimetric gravity data. The MDTs computed with GECO and XGM2019e_2159 are relatively flat compared to those calculated from EGM2008. This corresponds to the properties of MDT models shown in Figure 7, where significant variations are observed in the east-west direction when EGM2008 is used as the reference model. For MDTs computed from these three GGMs, the models determined with different gravity data show relatively consistent patterns, with the exception of the Discovery Reef $\left(111.6^{\circ} \mathrm{E}\right)$, see Figure $9 \mathrm{a}, 9 \mathrm{~b}$, and $9 \mathrm{c}$. In this instance, the discrepancy between the MDT computed from a GGM alone and that modeled by combining the airborne gravity data is $\sim 6 \mathrm{~cm}$ when EGM2008 and GECO is applied, and 4 cm when XGM2019e_2159 is used. Similarly, the spike-like errors $(>3 \mathrm{~cm})$ are noticeable in regions near the Discovery Reef in the MDTs computed by only combining the altimetric gravity data. These results show that airborne gravimetry may be necessary for MDT determination with centimeter-level accuracy over island areas. Figure 9d shows the geodetic and oceanic MDTs along latitude $16.2^{\circ} \mathrm{N}$, where the differences among different MDTs reach a magnitude of several centimeters. Similarly, the oceanic MDT displays smoother patterns than the geodetic models. The inconsistencies among different geodetic MDTs reach several centimeters, and the prominent differences are seen at east of $112.5^{\circ} \mathrm{E}$. A better mutual agreement 

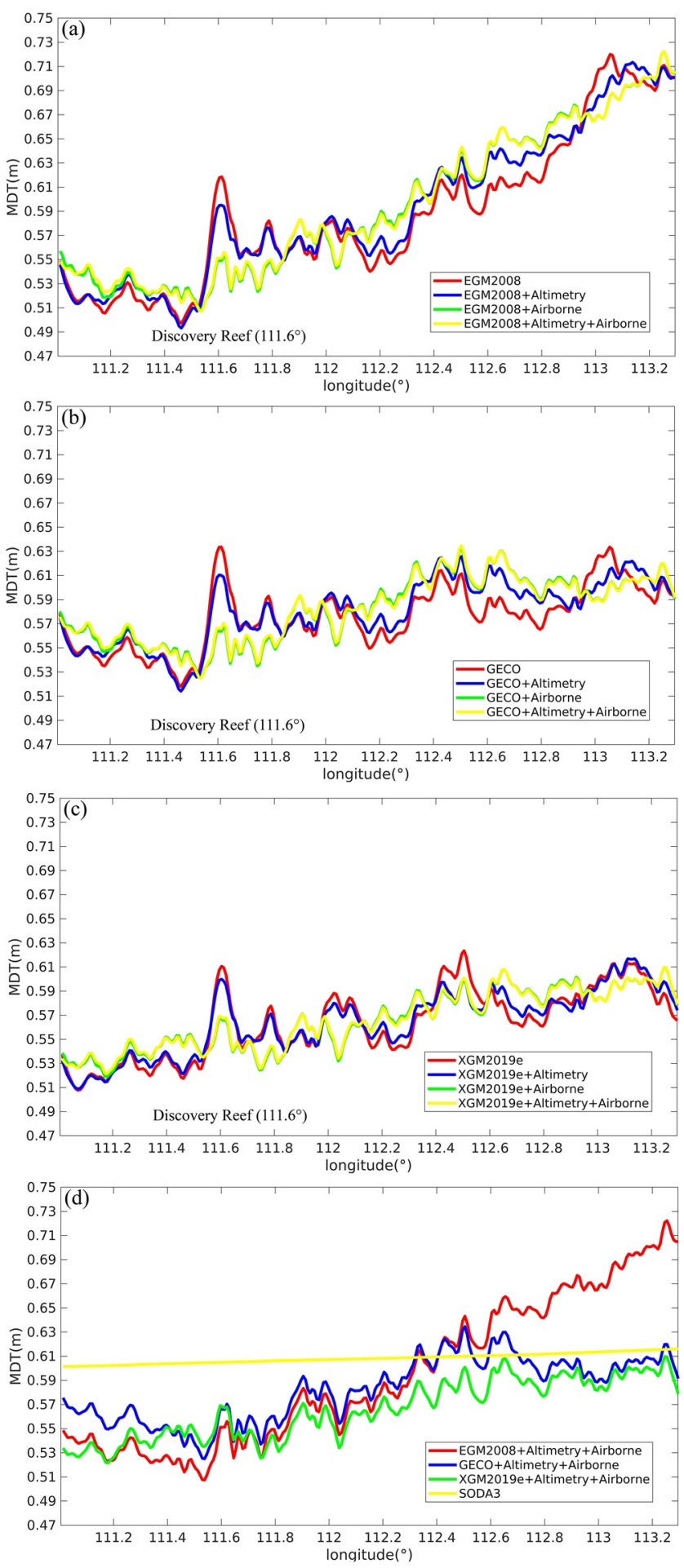

Figure 9. Profiles of different mean dynamic topographys (MDTs) along latitude $16.2^{\circ} \mathrm{N}$. is also found in MDTs modeled from GECO and XGM2019e_2159 than from EGM2008.

It is worth mentioning that significant discrepancies up to decimeter level are observed among the MDTs computed from different GGMs (Figure 7); while, the misfits among various regional/global quasi-geoid models calculated from different GGMs are not that significant when compared with the altimeter-derived quasi-geoid heights, as shown in Figure 6 and the statistics in Table 4. The reason is that the information of a GGM has been used in the altimeter data preprocessing (see Section 2.4), where the quasi-geoid signals synthesized from a GGM (up to $\mathrm{d} / \mathrm{o}$ 1080) and the dynamic topography are removed from the sea surface heights to compute the residual quasi-geoid heights. After that, the crossover adjustment is applied to reduce the tilts and biases, which largely reduce the biases between the geometric quasi-geoid heights derived from the altimeters and GGM-derived quasi-geoid heights. On the other hand, when we compute the geodetic MDTs, the situation is different. Since the full quasi-geoid signals are used to compute the geodetic MDTs; as such, the long-wavelength discrepancies among different GGMs are observed in MDT determination.

\subsection{Geostrophic Current Comparison}

The MDTs computed with different reference models exhibit heterogeneous structures (see Figure 7), although the local gravity data are used to regional enhancement. We model the local gravity field using the RCR method; as such, the long-wavelength discrepancies among different GGMs are observed in MDT determination. To assess those MDTs, the geostrophic velocities are computed, which are then compared with existing model and independent ocean data. Since the MDT modeled with the airborne gravity data alone closely agrees with the one computed by additionally combining the altimetric gravity data, we use the airborne-only solution for comparison. The MDTs that are modeled by combining the airborne gravimetric measurements (A) based on EGM2008, GECO, and XGM2019e_2159 are denoted as MDT_EGM2008_A, MDT_GECO_A, and MDT_XGM2019e_A, respectively.

CNES-CLS18MDT (Mulet et al., 2021) and three ocean models are introduced. These include the SODA3, ocean reanalysis product of the European Center for Medium-Range Weather Forecasts, version 5 (ECMWF ORAS5) (Zuo et al., 2017), and Ocean Circulation and Climate Advanced Modeling Project (OCCAM) (Fox \& Haines, 2003). CNES-CLS18MDT is a synthetic model estimated using CNES-CLS15 MSS and GOCO05S (Mayer-Gürr et al., 2015) as the rudimentary solution. It was further synthesized using in situ data to enhance short-wavelength content (Rio et al., 2011, 2014). This model refers to 1993-2012, with a spatial resolution of $0.125^{\circ}(\sim 15 \mathrm{~km})$. ORAS5 is an ocean reanalysis product from the ECMWF and was developed from the Ocean ReAnalysis Pilot 5, using the same ocean and sea ice model and data assimilation method. This model maps the ocean state at a $0.25^{\circ}$ horizontal resolution, and supplies monthly data from 1979 to 2017 . The OCCAM $\left(0.5^{\circ}\right.$ horizontal resolution) maps the ocean state from 1993 to 2004, and was developed using a hydrodynamic model forced with wind stresses from the ECMWF. 
An additional data set derived from an ocean data assimilation system in Asia, the Indian Ocean, and the western Pacific Ocean (AIPO), namely the AIPOcean data set (Yan et al., 2010, 2015), is used to assess the qualities of geostrophic currents determined from different models. AIPOcean was computed from the AVISO altimetric SLA, satellite-sensed sea surface temperature, and in situ temperature and salinity profiles. This model contains the daily averaged ocean current field from 1993 to 2006, with a horizontal resolution of $0.25^{\circ}$. A comparison with independent data showed that the quality of AIPOcean data was controlled well, which provided realistic structures of the ocean state (Yan et al., 2015). As AIPOcean data spans the 1993-2006 period, other models are referenced to the same period for the purposes of comparison. The time periods of MDTs computed from the high-degree GGMs, CNES-CLS18MDT, and OCCAM MDT, are referenced to 1993-2006 using the AVISO SLA data (Rio et al., 2011). Then, we use the MDT gradients to compute the geostrophic velocities at the ocean surface, and the used equations are seen in, for example, Hwang and Sung (2000). The geostrophic velocities determined from the high-degree GGMs and CNES-CLS18MDT have relatively high resolutions, and contain a significant amount of small-scale contents that cannot be resolved in AIPOcean data. Thus, we apply a Gaussian filter with a correlation length of $30 \mathrm{~km}$ to obtain a spectrally consistent comparison. For SODA3 and ORAS5, we average monthly files between 1993 and 2006 to derive surface currents.

Figure 10 shows the zonal velocities associated with different models, where real surface ocean circulation signals are observed. For instance, the structures in the northwest Paracel Islands are in line with the strong western boundary current, known as the SCS Western Boundary Current (e.g., Yang et al., 2002). The zonal velocities derived from the AIPOcean data range from -15.9 to $11.5 \mathrm{~cm} / \mathrm{s}$, with a mean of $-2.5 \mathrm{~cm} / \mathrm{s}$, and a $\mathrm{SD}$ of $5.5 \mathrm{~cm} / \mathrm{s}$. The comparisons between the values retrieved from AIPOcean and those derived from other models are not identical. The velocities estimated from MDT_EGM2008_A, MDT_GECO_A, MDT_XGM2019e_A, and SODA3 have smaller discrepancies against the AIPOcean data compared to other models, where the SD values of the misfits are between 2.8 and $3.3 \mathrm{~cm} / \mathrm{s}$ (see Table 5). The maximum amplitude of the velocities depicted in the AIPOcean data reaches $15 \mathrm{~cm} / \mathrm{s}$; whereas, a value smaller than $12.7 \mathrm{~cm} / \mathrm{s}$ is obtained with SODA3 and one larger than $16.0 \mathrm{~cm} / \mathrm{s}$ is derived from these three geodetic MDTs. The mutual comparisons show that the zonal velocities computed from these geodetic MDTs have comparable performances, though the structures of the velocities computed from different GGMs are not identical. The disparities between the AIPOcean data and the velocities derived from those geodetic MDTs are relatively prominent over the southeastern Paracel Islands. The differences in input data and methods for model development partly account for these differences. For example, AIPOcean was computed from the ensemble optimal interpolation method and various types of in situ data were assimilated. In contrast, the geodetic MDTs were computed from a purely geodetic method, without incorporating any in situ data.

OCCAM demonstrates stronger zonal mean circulation over the northern Paracel Islands than other models, with a maximum value of $\sim 20 \mathrm{~cm} / \mathrm{s}$. The performance of this model is slightly worse than the four models discussed above, where the SD of the misfits against the AIPOcean data increases to $4.3 \mathrm{~cm} / \mathrm{s}$. The SD of differences between the AIPOcean data and CNES-CLS18MDT increases to $6.2 \mathrm{~cm} / \mathrm{s}$, and large inconsistencies are observed south of $17.5^{\circ}$. The mean circulation of CNES-CLS18MDT in the northwest Paracel Islands is relatively smooth. This may be attributed to the application of a satellite-only GGM and the subsequent filtering procedure to derive the first-guess solution of CNES-CLS18MDT (Rio et al., 2011, 2014), which inevitably filtered out useful medium- and short-wavelength signals in MSS. Moreover, owing to the scarcity of in situ data over local areas, the signals extracted from these data may not fully compensate for the missed contents. ORAS5 has the largest variation among these models, and the SD of discrepancies against the AIPOcean data is $10.3 \mathrm{~cm} / \mathrm{s}$.

Figure 11 shows that the meridian velocities and the values retrieved from the AIPOcean data range from -10.5 to $13.8 \mathrm{~cm} / \mathrm{s}$, with a mean of $0.7 \mathrm{~cm} / \mathrm{s}$ and a SD of $3.5 \mathrm{~cm} / \mathrm{s}$. The meridian velocities derived from MDT_GECO_A and MDT_XGM2019e_A have smaller disparities against the AIPOcean data compared to the values derived from other models; the SD is 2.1 and $2.0 \mathrm{~cm} / \mathrm{s}$, respectively (see Table 6). This is better than that derived from MDT_EGM2008_A, by a magnitude of $\sim 1.5 \mathrm{~cm} / \mathrm{s}$. This is owing to the combination of GOCE data in developing GECO/XGM2019e_2019. It is notable that the meridian velocities computed from the geodetic MDT based on GECO/XGM2019e_2019 have better performances than the zonal ones. This may be mainly due to the configuration of satellite orbits of GRACE/GOCE missions, which affects 

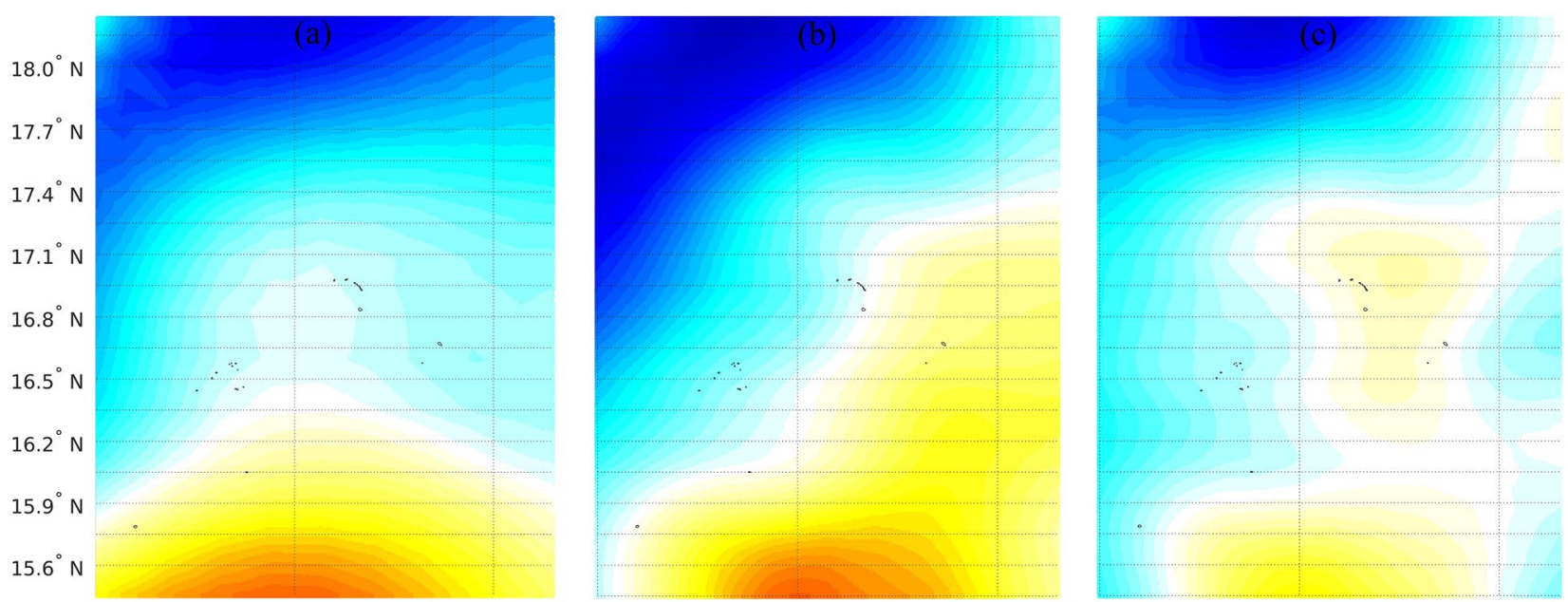

$111.0^{\circ} \mathrm{E} \quad 111.5^{\circ} \mathrm{E} \quad 112.0^{\circ} \mathrm{E} \quad 112.5^{\circ} \mathrm{E} \quad 113.0^{\circ} \mathrm{E} \quad 111.0^{\circ} \mathrm{E} \quad 111.5^{\circ} \mathrm{E} \quad 112.0^{\circ} \mathrm{E} \quad 112.5^{\circ} \mathrm{E} \quad 113.0^{\circ} \mathrm{E} \quad 111.0^{\circ} \mathrm{E} \quad 111.5^{\circ} \mathrm{E} \quad 112.0^{\circ} \mathrm{E} \quad 112.5^{\circ} \mathrm{E} \quad 113.0^{\circ} \mathrm{E}$
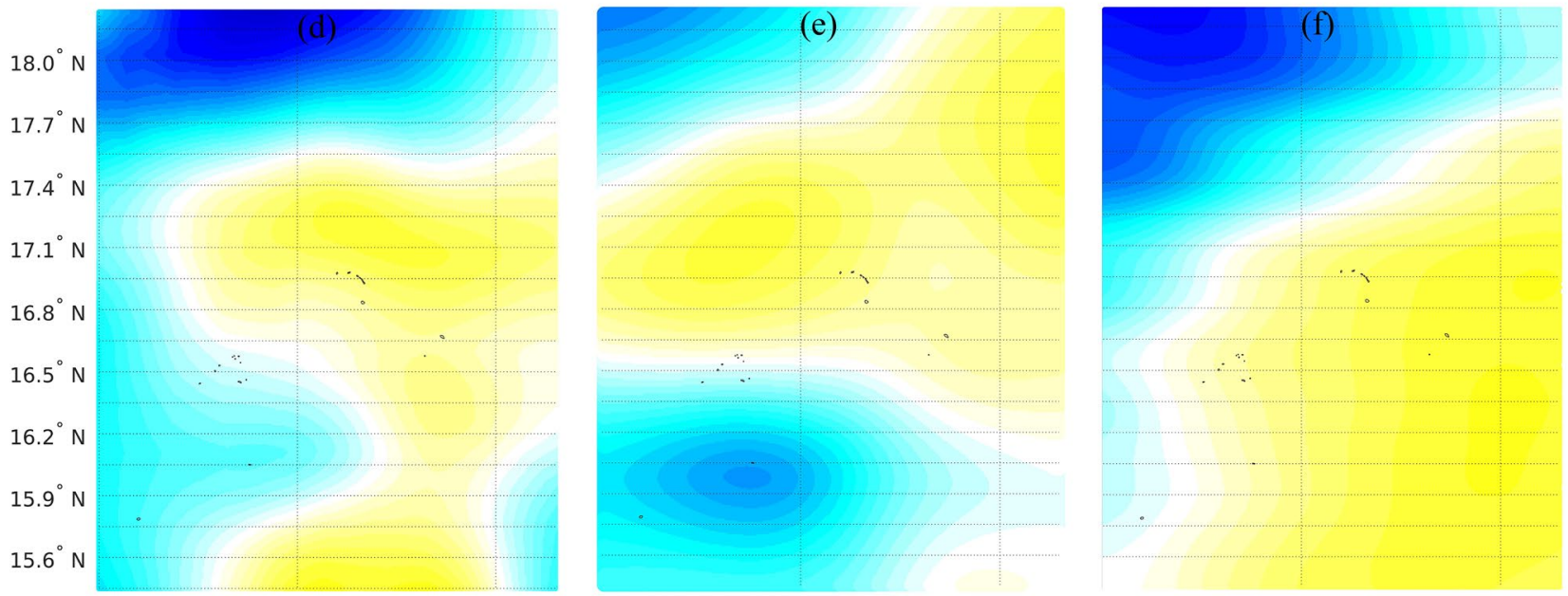

$111.0^{\circ} \mathrm{E} 111.5^{\circ} \mathrm{E} 112.0^{\circ} \mathrm{E} \quad 112.5^{\circ} \mathrm{E} \quad 113.0^{\circ} \mathrm{E} \quad 111.0^{\circ} \mathrm{E} \quad 111.5^{\circ} \mathrm{E} \quad 112.0^{\circ} \mathrm{E} \quad 112.5^{\circ} \mathrm{E} \quad 113.0^{\circ} \mathrm{E} \quad 111.0^{\circ} \mathrm{E} \quad 111.5^{\circ} \mathrm{E} \quad 112.0^{\circ} \mathrm{E} \quad 112.5^{\circ} \mathrm{E} \quad 113.0^{\circ} \mathrm{E}$
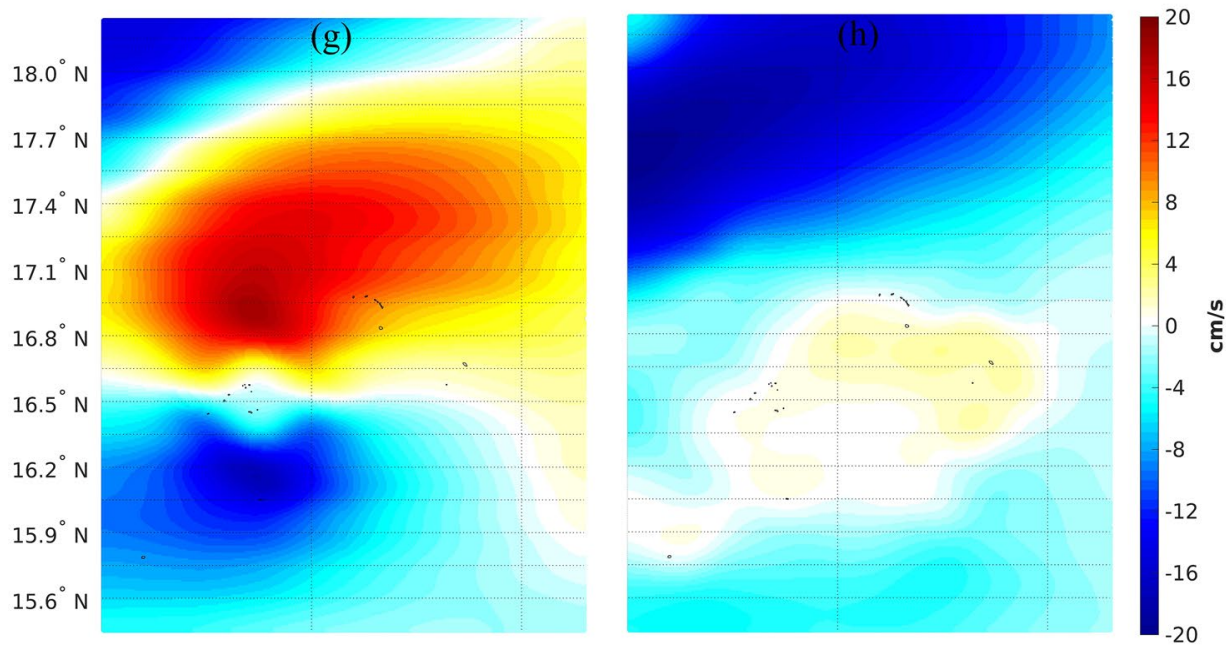

$111.0^{\circ} \mathrm{E} \quad 111.5^{\circ} \mathrm{E} \quad 112.0^{\circ} \mathrm{E} \quad 112.5^{\circ} \mathrm{E} \quad 113.0^{\circ} \mathrm{E} \quad 111.0^{\circ} \mathrm{E} \quad 111.5^{\circ} \mathrm{E} \quad 112.0^{\circ} \mathrm{E} \quad 112.5^{\circ} \mathrm{E} \quad 113.0^{\circ} \mathrm{E}$

Figure 10. Geostrophic zonal velocities derived from (a) AIPOcean data, (b) MDT_EGM2008_A, modeled with DTU18MSS and quasi-geoid computed by combining airborne gravity data based on EGM2008, (c) MDT_GECO_A, computed with DTU18MSS and quasi-geoid computed by using airborne data based on GECO, (d) MDT_XGM2019e_A, calculated from DTU18MSS and quasi-geoid computed by merging airborne data based on XGM2019e_2159, (e) CNESCLS18MDT, (f) SODA3, (g) ORAS5, and (h) OCCAM. 
Table 5

Statistics on the Differences Between the Geostrophic Zonal Velocities Derived From AIPOcean Data and Those Computed From Various Models (Unit: $\mathrm{cm} / S$ )

\begin{tabular}{lrrrr}
\hline & Max & Min & Mean & SD \\
\hline MDT_EGM2008_A & 6.5 & -7.8 & -0.5 & 2.9 \\
MDT_GECO_A & 5.7 & -8.0 & -0.6 & 2.8 \\
MDT_XGM2019e_A & 5.7 & -7.5 & -1.4 & 2.8 \\
CNES-CLS18MDT & 12.2 & -11.7 & -1.1 & 6.2 \\
SODA3 & 7.9 & -7.9 & -2.4 & 3.3 \\
ORAS5 & 19.0 & -19.2 & -3.3 & 10.3 \\
OCCAM & 14.8 & -5.7 & 2.9 & 4.3 \\
\hline
\end{tabular}

the error structures of GGM-derived quantities. As the orbit of GRACE/ GOCE is almost south-north oriented, the along-track data sampling is much denser than that in the across-track direction; and consequently, there are more high-quality data in meridian direction than in zonal direction. As a result, larger errors are observed in east-west direction than in north-south direction for GGM-derived quantities (Balmino, 2009; Bingham, Tscherning et al., 2011).

The meridian velocities derived from SODA3 slightly outperform the ones computed from MDT_EGM2008_A, where the SD of misfits against the AIPOcean data is $3.3 \mathrm{~cm} / \mathrm{s}$. CNES-CLS18MDT and OCCAM have comparable results with MDT_EGM2008_A, where the SD values of misfits are $\sim 3.6 \mathrm{~cm} / \mathrm{s}$. For ORAS5, the SD of discrepancies against the AIPOcean data increases to $4.0 \mathrm{~cm} / \mathrm{s}$.

\section{Conclusions}

We investigate the roles of satellite altimetric gravity data and airborne gravimetric observations in regional quasi-geoid/MDT refinement over island areas. The numerical experiments over the Paracel Islands in the northwestern South China Sea show that the combination of airborne gravity data enhances the local gravity field, and reduces the errors in the associated quasi-geoid, in comparison to the result directly derived from a GGM.

The local MDT directly computed from a high-degree GGM shows significant oscillations around island areas, which may cause errors exceeding $6 \mathrm{~cm}$ near islands. As such, this is an impediment for MDT recovery with centimeter-level accuracy. This problem is evident in the GGMs selected in this study, and other currently available models. In contrast, the incorporation of recently released altimetric gravity data slightly reduces the oscillations in the associated MDT, indicating that the use of altimetry data may slightly improve the short-wavelength signals of local MDT. However, the bubble-like errors are prominent near islands, suggesting that altimetry data alone may be inadequate for high-accuracy MDT recovery.

The combination of airborne data significantly reduces the errors in the associated MDT, demonstrating much smoother patterns than the MDT directly computed from a GGM and that computed by only combining the altimetric gravity data. The airborne survey samples the local gravity field at a denser resolution than altimetry data and overcomes the drawbacks of satellite altimetry near coasts and islands, which may be necessary for high-quality MDT recovery with centimeter-level accuracy over such regions. We notice that the airborne gravimetry plays a dominant role in local quasi-geoid/MDT refinement; and the additional signals introduced from the altimetric gravity data are marginal if the airborne data have been used for local refinement, which may have negligible effects on local MDT recovery with centimeter-level accuracy.

To assess the MDTs computed from different GGMs, the associated geostrophic currents are estimated and compared with existing model and ocean reanalysis data. The results show that the geostrophic velocities, which are determined by merging a high-degree GGM and airborne gravity data, are able to reconstruct surface ocean circulation signals. The mutual comparisons show that the geostrophic velocities determined from GECO/XGM2019e_2019 have a better fit with ocean data than those calculated from EGM2008, by $\sim 1.5 \mathrm{~cm} / \mathrm{s}$ when the meridian velocities are assessed. This suggests that the GOCE-based GGMs may be preferable as the reference models in MDT determination.

Future work involves several aspects in order to improve the local MDT. First, we use a global MSS model called DTU18MSS to compute local MDT. However, this model also suffers from the coast problem although it has incorporated SAR-based data from Sentinel-3A over coastal zones. By combining more high-quality SAR altimetry data from the missions like Sentinel-3A/B and Sentinel-6 as well as using the updated data preprocessing methods (like improved waveform retracking approach), a refined MSS model over the local region may be derived, which is beneficial for local MDT recovery. Moreover, the raw MDT is computed by removing the quasi-geoid from the MSS model. However, the spatial resolutions of the local quasi-geoid and MSS model are different, and spectral inconsistencies exist between these two data sets. Consequently, 

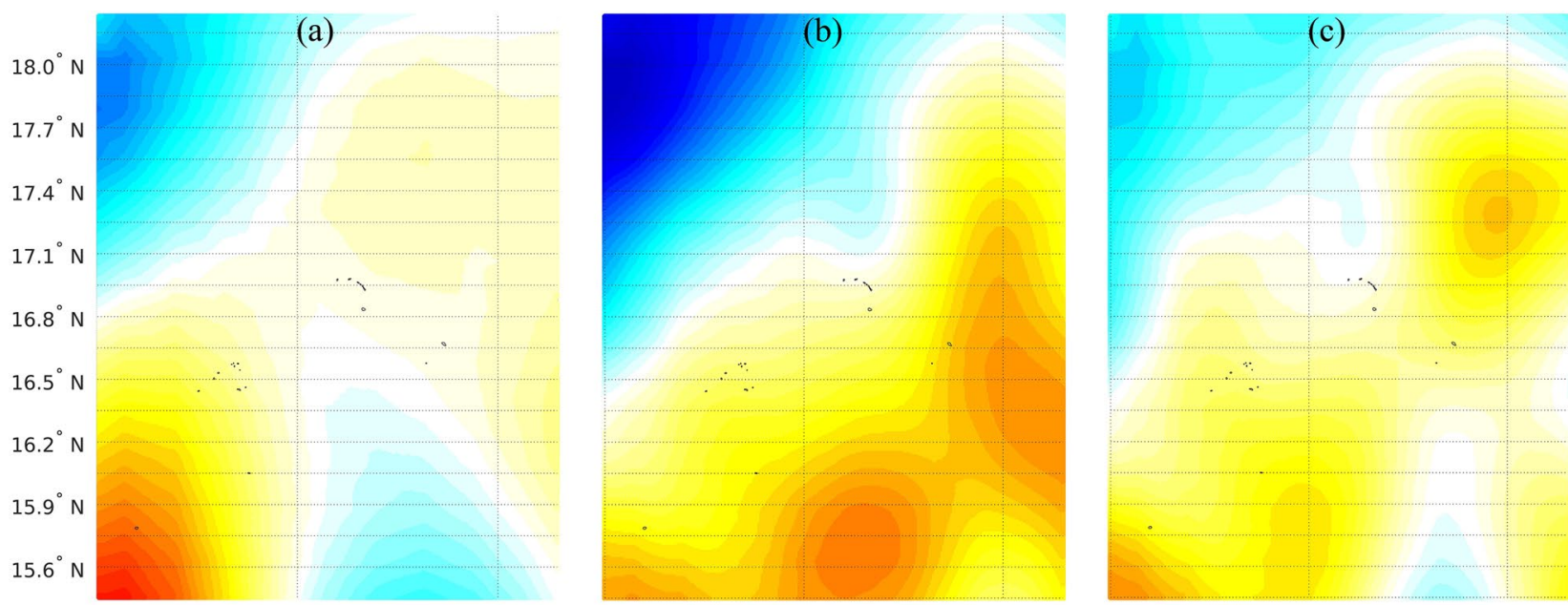

$111.0^{\circ} \mathrm{E} \quad 111.5^{\circ} \mathrm{E} \quad 112.0^{\circ} \mathrm{E} \quad 112.5^{\circ} \mathrm{E} \quad 113.0^{\circ} \mathrm{E}$

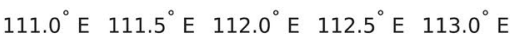

$111.0^{\circ} \mathrm{E} \quad 111.5^{\circ} \mathrm{E} \quad 112.0^{\circ} \mathrm{E} \quad 112.5^{\circ} \mathrm{E} \quad 113.0^{\circ} \mathrm{E}$

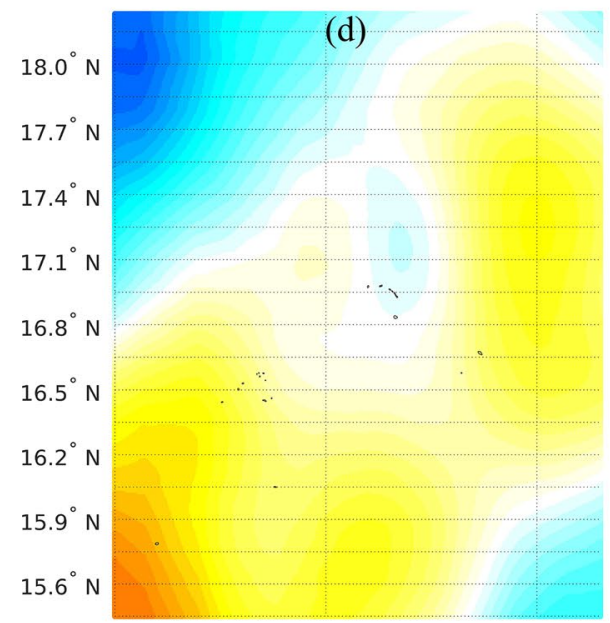

(e)
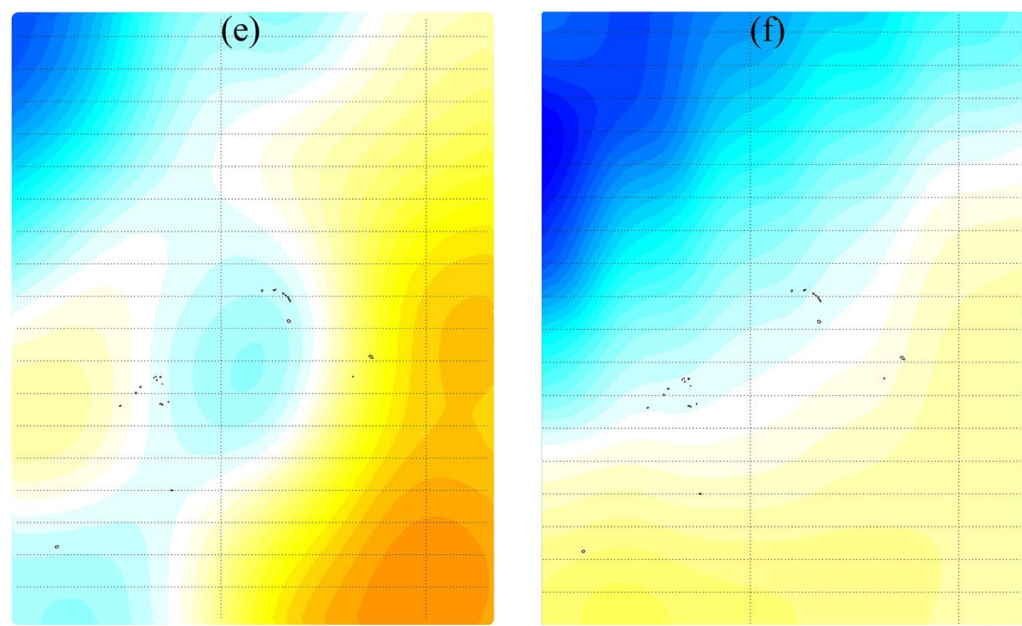

$111.0^{\circ} \mathrm{E} 111.5^{\circ} \mathrm{E} 112.0^{\circ} \mathrm{E} 112.5^{\circ} \mathrm{E} 113.0^{\circ} \mathrm{E} \quad 111.0^{\circ} \mathrm{E} \quad 111.5^{\circ} \mathrm{E} \quad 112.0^{\circ} \mathrm{E} \quad 112.5^{\circ} \mathrm{E} \quad 113.0^{\circ} \mathrm{E} \quad 111.0^{\circ} \mathrm{E} \quad 111.5^{\circ} \mathrm{E} \quad 112.0^{\circ} \mathrm{E} \quad 112.5^{\circ} \mathrm{E} \quad 113.0^{\circ} \mathrm{E}$
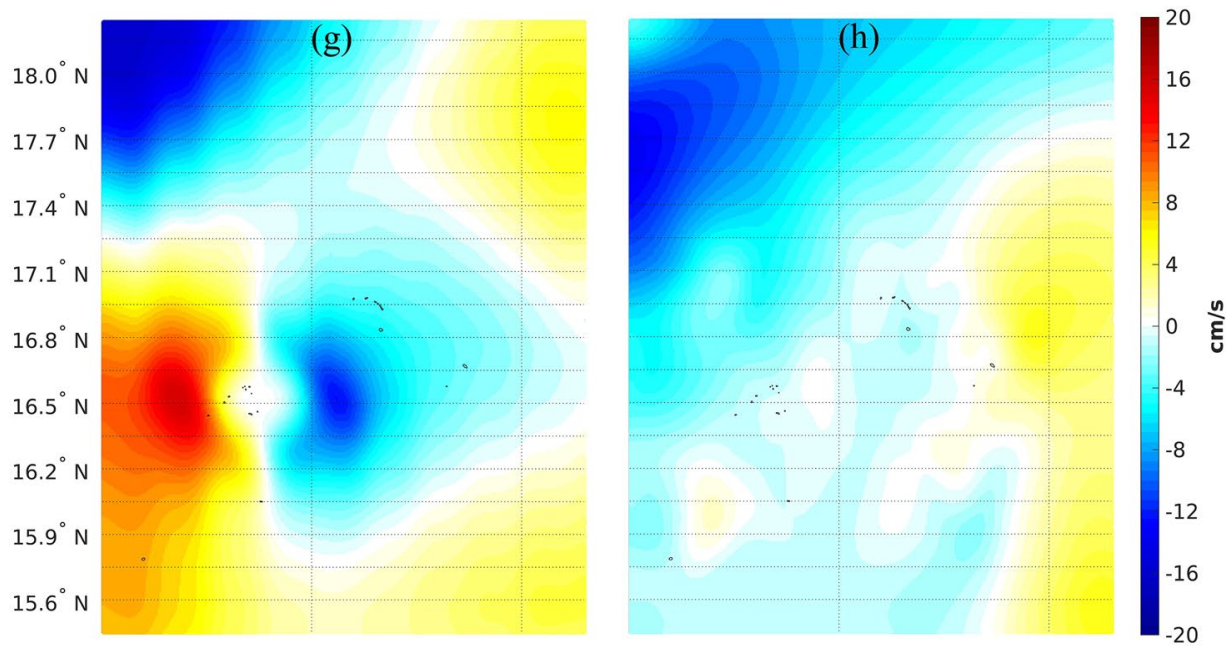

$111.0^{\circ} \mathrm{E} \quad 111.5^{\circ} \mathrm{E} \quad 112.0^{\circ} \mathrm{E} \quad 112.5^{\circ} \mathrm{E} \quad 113.0^{\circ} \mathrm{E} \quad 111.0^{\circ} \mathrm{E} \quad 111.5^{\circ} \mathrm{E} \quad 112.0^{\circ} \mathrm{E} \quad 112.5^{\circ} \mathrm{E} \quad 113.0^{\circ} \mathrm{E}$

Figure 11. Geostrophic meridian velocities derived from (a) AIPOcean data, (b) MDT_EGM2008_A, modeled with DTU18MSS and quasi-geoid computed by combining airborne gravity data based on EGM2008, (c) MDT_GECO_A, computed with DTU18MSS and quasi-geoid computed by using airborne data based on GECO, (d) MDT_XGM2019e_A, calculated from DTU18MSS and quasi-geoid computed by merging airborne data based on XGM2019e_2159, (e) CNESCLS18MDT, (f) SODA3, (g) ORAS5, and (h) OCCAM. 
Table 6

Statistics on the Differences Between the Geostrophic Meridian Velocities Derived From AIPOcean Data and Those Computed From Various Models (Unit: $\mathrm{cm} / \mathrm{S}$ )

\begin{tabular}{lrrrr}
\hline & Max & Min & Mean & SD \\
\hline MDT_EGM2008_A & 6.1 & -12.0 & -1.2 & 3.6 \\
MDT_GECO_A & 3.8 & -6.9 & -1.1 & 2.1 \\
MDT_XGM2019e_A & 2.6 & -7.7 & -1.0 & 2.0 \\
CNES-CLS18MDT & 12.0 & -7.8 & -0.2 & 3.6 \\
SODA3 & 9.4 & -6.9 & 2.2 & 3.3 \\
ORAS5 & 12.8 & -11.3 & 0.6 & 4.0 \\
OCCAM & 14.0 & -6.1 & 2.6 & 3.5 \\
\hline
\end{tabular}

the direct combination of local quasi-geoid and MSS model is imperfect and may cause aliasing problem. The implement of the objective analysis method (Rio et al., 2011, 2014) or the rigorous least-square based approach (Becker et al., 2014) to combine the quasi-geoid and MSS model may alleviate this problem.

\section{Appendix A: Choice of the Truncation d/o of a GGM}

The MDTs computed from the regional quasi-geoids modeled when XGM2019e_2159 is truncated to different d/o are seen in Figure A1. The edge effects are significant if XGM2019e_2159 is truncated to a low d/o; for instance, the edge effects dominate the boundary of study area when this model is truncated to $\mathrm{d} / \mathrm{o} 360$. When the reference model is truncated to $d / o$ 360, the medium- and short-wavelength signals that have the wavelengths shorter than $\sim 60 \mathrm{~km}$ cannot be recovered from this model. On the other hand, the size of the area determines what wavelengths cannot be estimated. Due to the limited size of this study area, the long- and medium-wavelength gravity field signals may not be recovered from the data inside this area, even though the airborne and altimetric gravity data have good coverage inside the area. As a result, the missed medium-wavelength signals in the reference model may not be fully compensated by combining the airborne and altimetric gravity data inside this area, and significant errors occur in the associated MDT. It is noteworthy that this is not only the issue for a high-degree GGM that truncated to a low degree, but also the concern when a satellite-only GGM is used as the reference model for gravity field modeling over this study area. For instance, we also find significant errors and edge effects existing in the associated MDTs when the recently released satellite-only GGMs, for example, GOCO05S (d/o 280) (Mayer-Gürr et al., 2015), GOCO06S (d/o 300) (Kvas et al., 2021), and GO_CONS_GCF_2_DIR_R6 (d/o 300) (Förste et al., 2019), are used as the reference models for quasi-geoid/ MDT modeling over this study area. Whereas, as the truncation of d/o of the reference model increases, more medium-wavelength signals are recovered from this model; and consequently, the edge effects gradually reduce, which almost disappear when the truncation of d/o increases to 1080. After that, the computed MDTs almost show consistent structures with regardless of the increase of the truncation of d/o. 

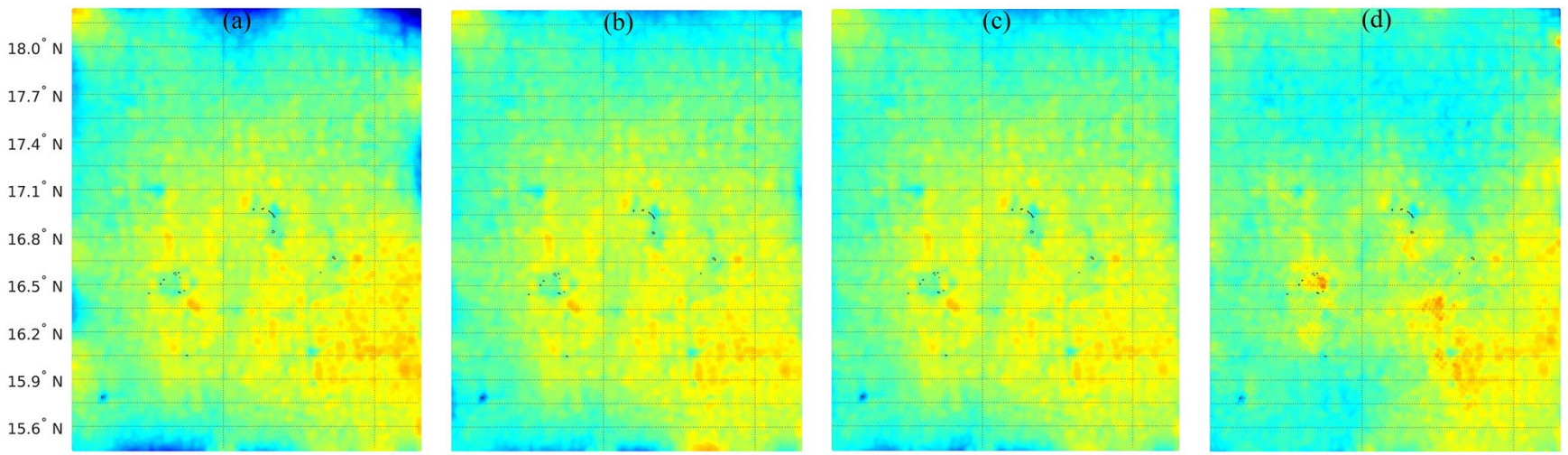

$111.0^{\circ} \mathrm{E} \quad 111.5^{\circ} \mathrm{E} \quad 112.0^{\circ} \mathrm{E} \quad 112.5^{\circ} \mathrm{E} \quad 113.0^{\circ} \mathrm{E} \quad 111.0^{\circ} \mathrm{E} \quad 111.5^{\circ} \mathrm{E} \quad 112.0^{\circ} \mathrm{E} \quad 112.5^{\circ} \mathrm{E} \quad 113.0^{\circ} \mathrm{E}$
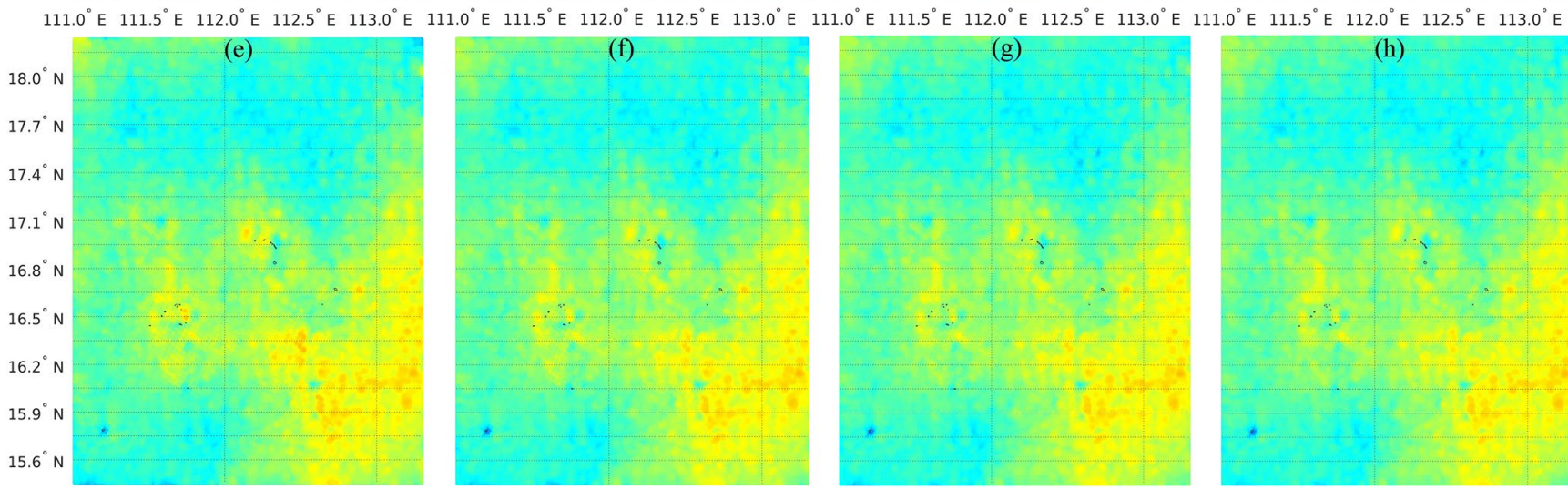

(h)

$111.0^{\circ} \mathrm{E} \quad 111.5^{\circ} \mathrm{E} \quad 112.0^{\circ} \mathrm{E} \quad 112.5^{\circ} \mathrm{E} \quad 113.0^{\circ} \mathrm{E} \quad 111.0^{\circ} \mathrm{E} \quad 111.5^{\circ} \mathrm{E} \quad 112.0^{\circ} \mathrm{E} \quad 112.5^{\circ} \mathrm{E} \quad 113.0^{\circ} \mathrm{E} \quad 111.0^{\circ} \mathrm{E} \quad 111.5^{\circ} \mathrm{E} \quad 112.0^{\circ} \mathrm{E} \quad 112.5^{\circ} \mathrm{E} \quad 113.0^{\circ} \mathrm{E} \quad 111.0^{\circ} \mathrm{E} \quad 111.5^{\circ} \mathrm{E} \quad 112.0^{\circ} \mathrm{E} \quad 112.5^{\circ} \mathrm{E} \quad 113.0^{\circ} \mathrm{E}$
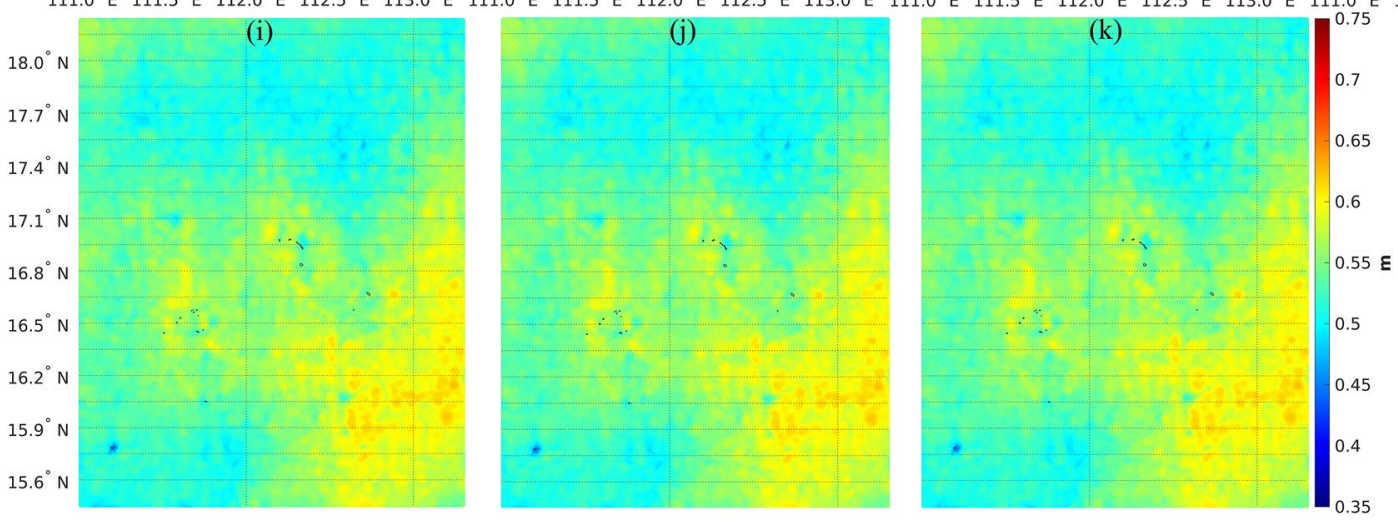

$111.0^{\circ} \mathrm{E} \quad 111.5^{\circ} \mathrm{E} \quad 112.0^{\circ} \mathrm{E} \quad 112.5^{\circ} \mathrm{E} \quad 113.0^{\circ} \mathrm{E} \quad 111.0^{\circ} \mathrm{E} \quad 111.5^{\circ} \mathrm{E} \quad 112.0^{\circ} \mathrm{E} \quad 112.5^{\circ} \mathrm{E} \quad 113.0^{\circ} \mathrm{E} \quad 111.0^{\circ} \mathrm{E} \quad 111.5^{\circ} \mathrm{E} \quad 112.0^{\circ} \mathrm{E} \quad 112.5^{\circ} \mathrm{E} \quad 113.0^{\circ} \mathrm{E}$

Figure A1. MDTs computed from the regional quasi-geoids modeled by using airborne gravity data when XGM2019e_2159 truncated to d/o 360 (a), 540 (b), 720 (c), 900 (d), 1080 (e), 1260 (f), 1440 (g), 1620 (h), 1800 (i), 1980 (j), and 2190/2159 (k) are used as the reference models, respectively.

Moreover, we study the degree-wise accumulated geoid error of XGM2019e_2159, see Figure A2. The geoid error of this model rises rapidly at low degrees, which reaches $\sim 3.04 \mathrm{~cm}$ by the degree of 1080 . Then, it increases slowly to $\sim 3.13 \mathrm{~cm}$ by the maximal degree. Considering that the commission error of XGM2019e_2159 increases slowly after d/o 1080, the use of a reference model that truncated to a higher d/o may not introduce more significant error. However, it is worth mentioning that error degree variances only supply a global mean of internal error and cannot be regarded as the realistic error estimate. 


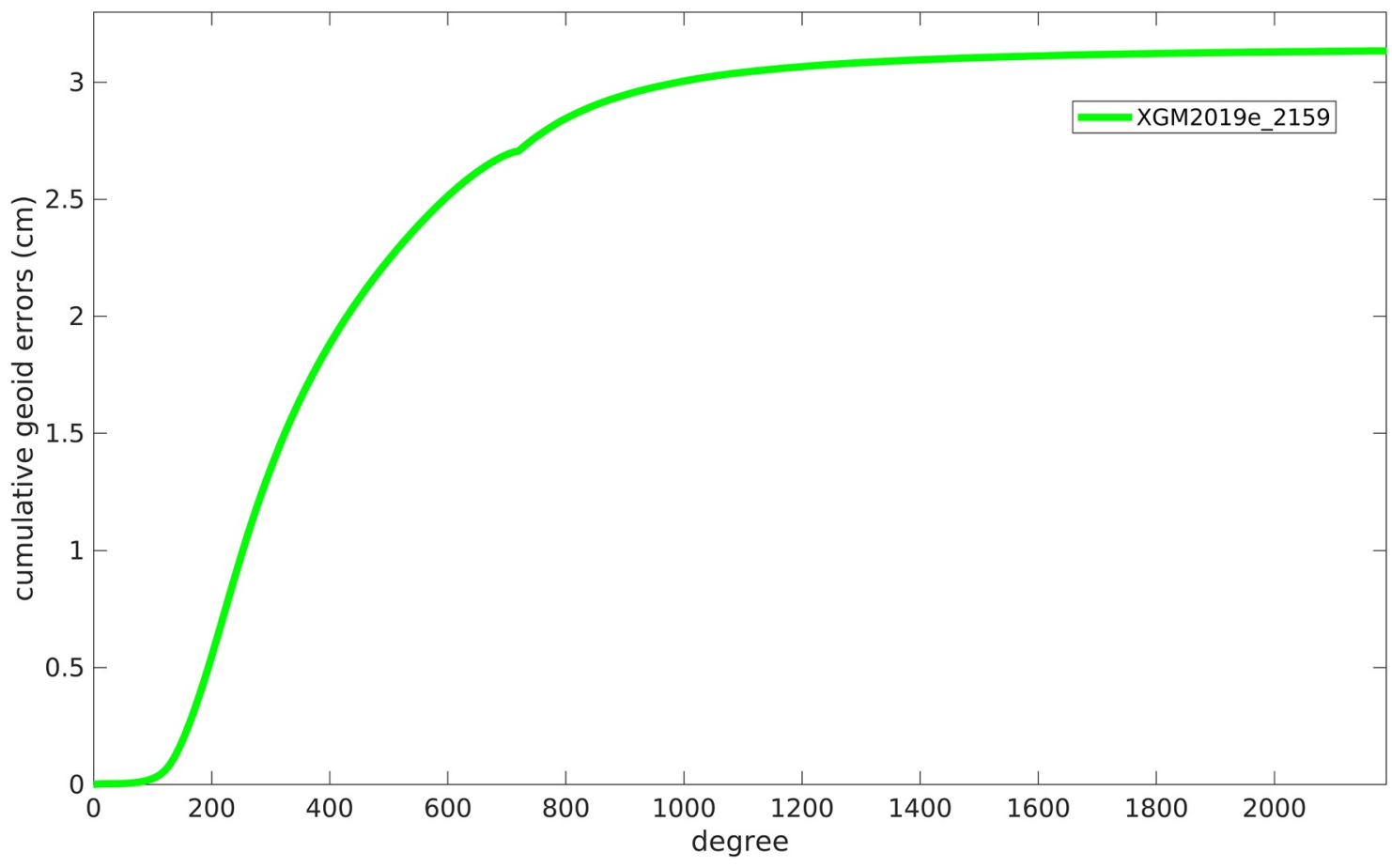

Figure A2. Cumulative geoid errors of XGM2019e_2159 as a function of spherical expansion degree.

Finally, we compare the geostrophic velocities derived from these MDTs with independent ocean data, where the AIPOcean data (details of AIPOcean data and the way we compute geostrophic velocities from geodetic MDT are seen in Section 3.3) is used. Figure A3 shows the geostrophic zonal velocities computed from different MDTs, and Table A1 provides the statistics of the differences between the AIPOcean data and the zonal velocities computed from those MDTs. We see that the velocities derived from the MDT computed when XGM2019e_2159 is truncated to d/o 360 have the worst performance, where the SD of the misfits is $\sim 6.7 \mathrm{~cm} / \mathrm{s}$. As the truncation of $\mathrm{d} / \mathrm{o}$ increases, the fit with the AIPOcean data improves. The SD of the misfits reduces to $\sim 4.0,3.5,2.9$, and $2.8 \mathrm{~cm} / \mathrm{s}$, when the truncation of $\mathrm{d} / \mathrm{o}$ is $540,720,900$, and 1080, respectively. Whereas, when XGM2019e_2159 is truncated to d/o 1260 or higher, we find the SD values of the misfits are almost the same, that is, approximately $3.0 \mathrm{~cm}$, which are slightly worse than the result derived when XGM2019e_2159 is truncated to d/o 1080. The meridian velocities derived from different MDTs are seen in Figure A4, and Table A2 provides the statistics, where we see that the MDTs modeled when the reference model is truncated to $\mathrm{d} / \mathrm{o} 720$ or higher have the comparable performances. It is note that the qualities of the MDTs derived from the reference models that truncated to relative high d/o may not be discriminated, due to the limited resolution of the AIPOcean data.

As we discussed above, when we choose the optimal truncated d/o, we first need to assure that the full-wavelength quasi-geoid signals can be recovered, and no significant edge effects propagate into the regional solutions. In the meanwhile, we should reduce the commission error from the reference model as much as possible. Moreover, the quality of the computed MDT should be guaranteed. In this manner, the truncation of d/o of XGM2019e_2159 is chosen as 1080, reaching a compromise among these three aspects. 

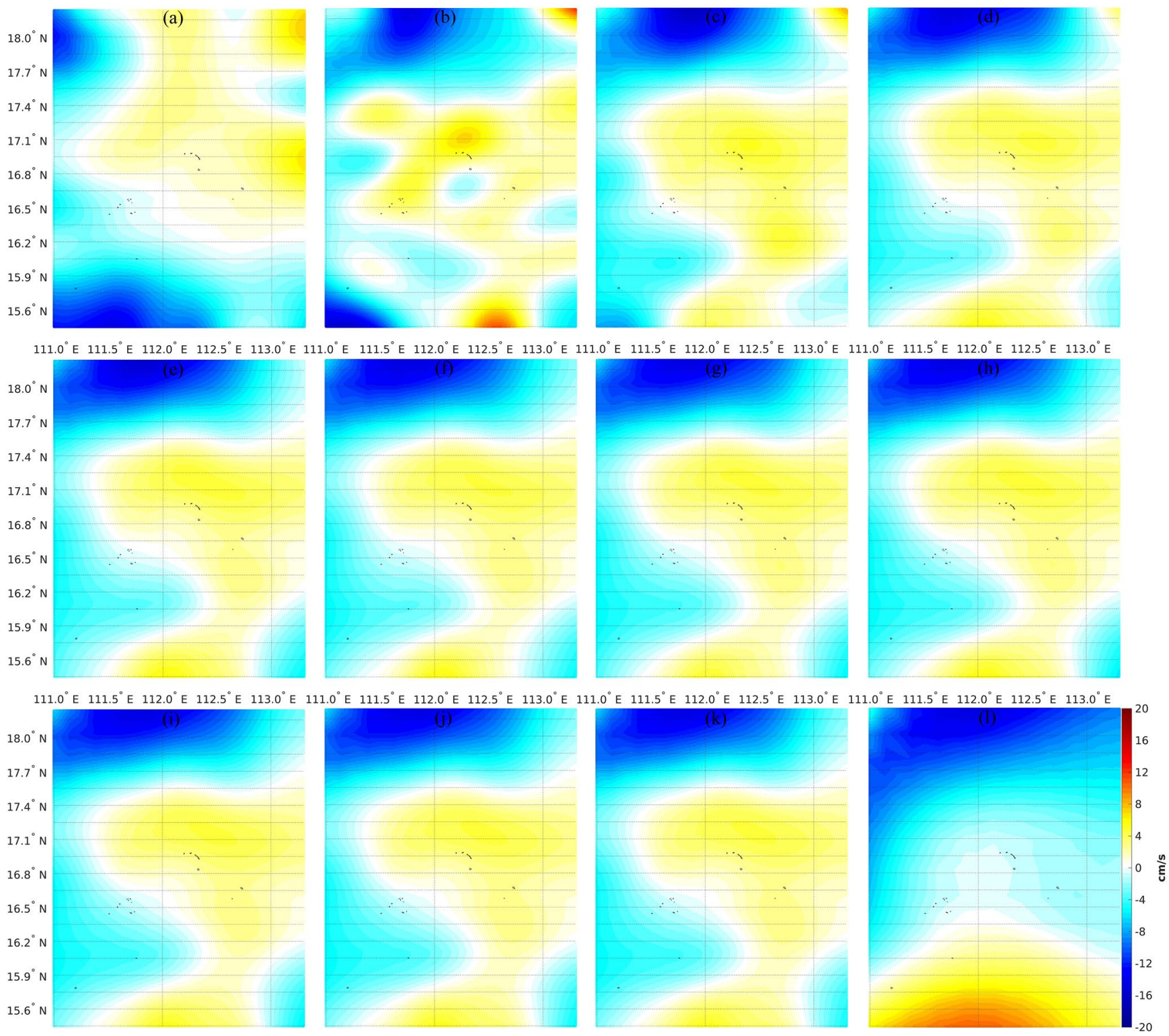

$111.0^{\circ} \mathrm{E} \quad 111.5^{\circ} \mathrm{E} \quad 112.0^{\circ} \mathrm{E} \quad 112.5^{\circ} \mathrm{E} \quad 113.0^{\circ} \mathrm{E} \quad 111.0^{\circ} \mathrm{E} \quad 111.5^{\circ} \mathrm{E} \quad 112.0^{\circ} \mathrm{E} \quad 112.5^{\circ} \mathrm{E} \quad 113.0^{\circ} \mathrm{E} \quad 111.0^{\circ} \mathrm{E} \quad 111.5^{\circ} \mathrm{E} \quad 112.0^{\circ} \mathrm{E} \quad 112.5^{\circ} \mathrm{E} \quad 113.0^{\circ} \mathrm{E} \quad 111.0^{\circ} \mathrm{E} \quad 111.5^{\circ} \mathrm{E} \quad 112.0^{\circ} \mathrm{E} \quad 112.5^{\circ} \mathrm{E} \quad 113.0^{\circ} \mathrm{E}$

Figure A3. Geostrophic zonal velocities computed from the regional MDTs modeled by using airborne gravity data when XGM2019e_2159 truncated to d/o 360 (a), 540 (b), 720 (c), 900 (d), 1080 (e), 1260 (f), 1440 (g), 1620 (h), 1800 (i), 1980 (j), and 2190/2159 (k) are used as the reference models, respectively; and the zonal velocities derived from AIPOcean data (l).

\section{Table A1}

Statistics on the Differences Between the Geostrophic Zonal Velocities Derived From AIPOcean Data and Those Computed From the Regional MDTs When XGM2019e_2159 Truncated to Different d/o are Used as the Reference Models (unit: $\mathrm{cm} / \mathrm{s}$ )

\begin{tabular}{lcccc}
\hline Truncated d/o & Max & Min & Mean & SD \\
\hline 360 & 22.1 & -17.9 & -1.7 & 6.7 \\
540 & 22.0 & -20.8 & -1.7 & 4.0 \\
720 & 13.8 & -17.6 & -1.7 & 3.5 \\
900 & 7.5 & -7.8 & -1.5 & 2.9
\end{tabular}


Table A1

Continued

\begin{tabular}{lcccc}
\hline Truncated d/o & Max & Min & Mean & SD \\
\hline 1080 & 5.7 & -7.5 & -1.4 & 2.8 \\
1260 & 7.1 & -7.3 & -1.4 & 3.0 \\
1440 & 7.7 & -7.1 & -1.4 & 3.0 \\
1620 & 7.7 & -7.2 & -1.4 & 3.0 \\
1800 & 7.5 & -6.7 & -1.4 & 3.0 \\
1980 & 7.1 & -6.8 & -1.4 & 3.0 \\
2190 & 6.8 & -6.9 & -1.4 & 3.0 \\
\hline
\end{tabular}
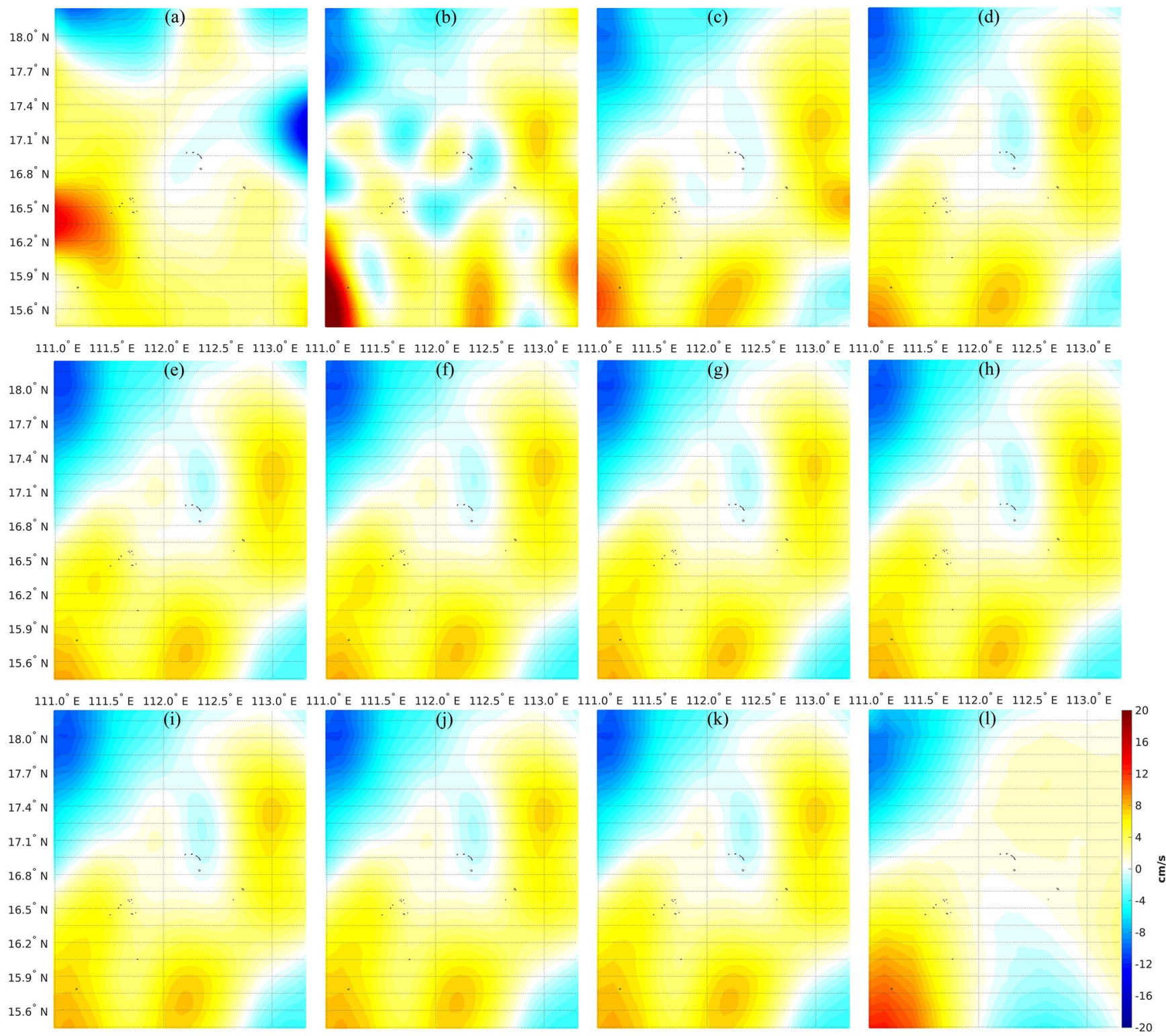

$111.0^{\circ} \mathrm{E} \quad 111.5^{\circ} \mathrm{E} \quad 112.0^{\circ} \mathrm{E} \quad 112.5^{\circ} \mathrm{E} \quad 113.0^{\circ} \mathrm{E} \quad 111.0^{\circ} \mathrm{E} \quad 111.5^{\circ} \mathrm{E} \quad 112.0^{\circ} \mathrm{E} \quad 112.5^{\circ} \mathrm{E} \quad 113.0^{\circ} \mathrm{E} \quad 111.0^{\circ} \mathrm{E} \quad 111.5^{\circ} \mathrm{E} \quad 112.0^{\circ} \mathrm{E} \quad 112.5^{\circ} \mathrm{E} \quad 113.0^{\circ} \mathrm{E} \quad 111.0^{\circ} \mathrm{E} \quad 111.5^{\circ} \mathrm{E} \quad 112.0^{\circ} \mathrm{E} \quad 112.5^{\circ} \mathrm{E} \quad 113.0^{\circ} \mathrm{E}$

Figure A4. Geostrophic meridian velocities computed from the regional MDTs modeled by using airborne gravity data when XGM2019e_2159 truncated to d/o 360 (a), 540 (b), 720 (c), 900 (d), 1080 (e), 1260 (f), 1440 (g), 1620 (h), 1800 (i), 1980 (j), and 2190/2159 (k) are used as the reference models, respectively; and the meridian velocities derived from AIPOcean data (l). 


\begin{tabular}{|c|c|c|c|c|}
\hline Truncated d/o & $\operatorname{Max}$ & Min & Mean & SD \\
\hline 360 & 14.7 & -11.4 & -1.0 & 3.2 \\
\hline 540 & 6.9 & -12.9 & -0.8 & 2.8 \\
\hline 720 & 2.0 & -7.7 & -1.1 & 2.0 \\
\hline 900 & 2.9 & -7.7 & -1.0 & 2.0 \\
\hline 1080 & 2.6 & -7.7 & -1.0 & 2.0 \\
\hline 1260 & 2.6 & -7.6 & -1.0 & 2.0 \\
\hline 1440 & 2.8 & -7.7 & -1.0 & 2.0 \\
\hline 1620 & 2.2 & -7.7 & -1.0 & 2.0 \\
\hline 1800 & 2.2 & -7.8 & -1.0 & 2.0 \\
\hline 1980 & 2.2 & -7.8 & -1.0 & 2.0 \\
\hline 2190 & 2.1 & -7.8 & -1.0 & 2.0 \\
\hline
\end{tabular}

\section{Data Availability Statement}

Airborne gravity data are provided by the First Geodetic Surveying Brigade of the Ministry of Natural Resources of China. DTU17GRA and DTU18MSS and the associated error grids are available on https://ftp. space.dtu.dk/pub. All global geopotential models can be publicly accessed from http://icgem.gfz-potsdam. de/home. Altimetry data for quasi-geoid model assessment are obtained from Radar Altimeter Database System (RADS) and are freely available through http://rads.tudelft.nl/rads/rads.shtml. CNES-CLS18MDT and AVISO sea level anomalies are publicly accessed from https://www.aviso.altimetry.fr/en/data/products.html. SODA3 is available on https://www.soda.umd.edu, ORAS5 is accessed from http://icdc.cen. uni-hamburg.de/thredds/catalog/ftpthredds/EASYInit/oras5/ORCA025/sossheig/opa4/catalog.html, and AIPOcean is available at http://www.argo.org.cn.

\section{Acknowledgments}

The authors would like to give our sincerest thanks to the two anonymous reviewers for their constructive suggestions and comments, which are of great value for improving the manuscript. The authors also thank the Editor Paul Tregoning and an Associate Editor for their kind assistances and beneficial comments. The authors are grateful for the kind support from the editorial office. The authors gratefully acknowledge the First Geodetic Surveying Brigade of the Ministry of Natural Resources of China for providing the airborne gravity data. The authors thank Prof. Roland Klees and Dr. Cornelis Slobbe from Delft University of Technology for providing part of the original software. This study was supported by the Natural Science Foundation of Jiangsu Province, China (No. BK20190498), the Fundamental Research Funds for the Central Universities (No. B200202019), the National Natural Science Foundation of China (No. 42004008, 41830110, 41931074, 41974016), and the State Scholarship Fund from Chinese Scholarship Council (No. 201306270014).

\section{References}

Albertella, A., Savcenko, R., Janjić, T., Rummel, R., Bosch, W., \& Schröter, J. (2012). High resolution dynamic ocean topography in the Southern Ocean from GOCE. Geophysical Journal International, 190(2), 922-930. https://doi.org/10.1111/j.1365-246X.2012.05531.X Andersen, O. B., \& Knudsen, P. (2009). DNSC08 mean sea surface and mean dynamic topography models. Journal of Geophysical Research, 114, C11001. https://doi.org/10.1029/2008JC005179

Andersen, O. B., \& Knudsen, P. (2019). International association of geodesy symposia. Springer. https://doi.org/10.1007/1345_2019_65 Andersen, O. B., Knudsen, P., Kenyon, S., Factor, J. K., \& Holmes, S. (2013). The DTU13 global marine gravity field-first evaluation. OSTST Meeting.

Andersen, O. B., Knudsen, P., \& Stenseng, L. (2018). A new DTU18 MSS mean sea surface-improvement from SAR altimetry. 25 years of progress in radar altimetry symposium. Portugal.

Andersen, O. B., Nielsen, K., Knudsen, P., Hughes, C. W., Bingham, R., Fenoglio-Marc, L., et al. (2018). Improving the coastal mean dynamic topography by geodetic combination of tide gauge and satellite altimetry. Marine Geodesy, 41(6), 517-545. https://doi.org/10.10 80/01490419.2018.1530320

Andersen, O. B., \& Scharroo, R. (2011). Range and geophysical corrections in coastal regions: And implications for mean sea surface determination, In J. Benveniste, et al (Eds.), In Coastal altimetry. Springer. https://doi.org/10.1007/978-3-642-12796-0_5

Balmino, G. (2009). Efficient propagation of error covariance matrices of gravitational models: Application to GRACE and GOCE. Journal of Geodesy, 83(10), 989-995. https://doi.org/10.1007/s00190-009-0317-2

Becker, S., Brockmann, J. M., \& Schuh, W. D. (2014). Mean dynamic topography estimates purely based on GOCE gravity field models and altimetry. Geophysical Research Letters, 41(6), 2063-2069. https://doi.org/10.1002/2014GL059510

Bingham, R. J., \& Haines, K. (2006). Mean dynamic topography: Intercomparisons and errors. Philosophical Transactions of the Royal Society A, 364(1841), 903-916. https://doi.org/10.1098/rsta.2006.1745

Bingham, R. J., Haines, K., \& Hughes, C. W. (2008). Calculating the ocean's mean dynamic topography from a mean sea surface and a geoid. Journal of Atmospheric and Oceanic Technology, 25(10), 1808-1822. https://doi.org/10.1175/2008JTECHO568.1

Bingham, R. J., Knudsen, P., Andersen, O. B., \& Pail, R. (2011). An initial estimate of the North Atlantic steady-state geostrophic circulation from GOCE. Geophysical Research Letters, 38, L01606. https://doi.org/10.1029/2010GL045633

Bingham, R. J., Tscherning, C., \& Knudsen, P. (2011). An initial investigation of the GOCE error variance covariance matrices in the context of the GOCE user toolbox project. Proceedings of 4th international GOCE user workshop European space agency.

Brockmann, J. M., Schubert, T., \& Schuh, W. D. (2021). An improved model of the Earth's static gravity field solely derived from reprocessed GOCE data. Surveys in Geophysics, 42, 277-316. https://doi.org/10.1007/s10712-020-09626-0 
Brockmann, J. M., Zehentner, N., Höck, E., Pail, R., Loth, I., Mayer-Gürr, T., \& Schuh, W.-D. (2014). EGM_TIM_RL05: An independent geoid with centimeter accuracy purely based on the GOCE mission. Geophysical Research Letters, 41, 8089-8099. https://doi. org/10.1002/2014GL061904

Brown, G. (1977). The average impulse response of a rough surface and its applications. IEEE Journal of Oceanic Engineering, 2(1), 67-74. https://doi.org/10.1109/JOE.1977.1145328

Bruinsma, S. L., Förste, C., Abrikosov, O., Marty, J. C., Rio, M. H., Mulet, S., \& Bonvalot, S. (2013). The new ESA satellite-only gravity field model via the direct approach. Geophysical Research Letters, 40, 3607-3612. https://doi.org/10.1002/grl.50716

Carton, J. A., Chepurin, G. A., \& Chen, L. (2018). SODA3: A new ocean climate reanalysis. Journal of Climate, 31(17), 6967-6983. https:// doi.org/10.1175/JCLI-D-18-0149.1

Deng, X., \& Featherstone, W. E. (2006). A coastal retracking system for satellite radar altimeter waveforms: Application to ERS2 around Australia. Journal of Geophysical Research, 111, C06012. https://doi.org/10.1029/2005JC003039

Farr, T. G., Rosen, P. A., Caro, E., Crippen, R., Duren, R., Hensley, S., et al. (2007). The shuttle radar topography mission. Review of Geophysics, 45(2), RG2004. https://doi.org/10.1029/2005RG000183

Farrell, S. L., McAdoo, D. C., Laxon, S. W., Zwally, H. J., Yi, D., Ridout, A., \& Giles, K. (2012). Mean dynamic topography of the Arctic Ocean. Geophysical Research Letters, 39, L01601. https://doi.org/10.1029/2011GL050052

Featherstone, W. E. (2010). Satellite and airborne gravimetry: Their role in geoid determination and some suggestions. In R. Lane (Ed.), Airborne gravity 2010. Geoscience Australia. Canberra.

Featherstone, W. E., \& Filmer, M. S. (2012). The north-south tilt in the Australian Height Datum is explained by the ocean's mean dynamic topography. Journal of Geophysical Research, 117(C8), C08035. https://doi.org/10.1029/2012JC007974

Featherstone, W. E., McCubbine, J. C., Brown, N. J., Claessens, S. J., Filmer, M. S., \& Kirby, J. F. (2018). The first Australian gravimetric quasigeoid model with location-specific uncertainty estimates. Journal of Geodesy, 92(2), 149-168. https://doi.org/10.1007/ s00190-017-1053-7

Filmer, M. S., Hughes, C. W., Woodworth, P. L., Featherstone, W. E., \& Bingham, R. J. (2018). Comparisons between geodetic and oceanographic approaches to estimate mean dynamic topography for vertical datum unification: Evaluation at Australia tide gauge. Journal of Geodesy, 92(12), 1413-1437. https://doi.org/10.1007/s00190-018-1131-5

Forsberg, R. (1984). A study of terrain reductions, density anomalies and geophysical inversion methods in gravity field modelling Report No. 355. Department of Geodetic Science and Surveying, The Ohio State University.

Forsberg, R., Olesen, A. V., Alshamsi, A., Gidskehaug, A., Ses, S., Kadir, M., \& Peter, B. (2012). Airborne gravimetry survey for the marine area of the United Arab Emirates. Marine Geodesy, 35(3), 221-232. https://doi.org/10.1080/01490419.2012.672874

Forsberg, R., Skourup, H., Andersen, O. B., Knudsen, P., Laxon, S. W., Ridout, A., et al. (2007). Combination of spaceborne, airborne and in-situ gravity measurements in support of Arctic sea ice thickness mapping. 7. Danish National Space Center.

Förste, C., Abrykosov, O., Bruinsma, S., Dahle, C., König, R., \& Lemoine, J.-M. (2019). ESA's Release 6 GOCE gravity field model by means of the direct approach based on improved filtering of the reprocessed gradients of the entire mission. GFZ Data Services. https://doi. org/10.5880/ICGEM.2019.004

Förste, C., Bruinsma, S. L., Abrikosov, O., Lemoine, J. M., Schaller, T., Götze, H. J., et al. (2014). EIGEN-6C4 the latest combined global gravity field model including GOCE data up to degree and order 2190 of GFZ Potsdam and GRGS Toulouse. The 5th GOCE user workshop.

Fox, A. D., \& Haines, K. (2003). Interpretation of water transformations diagnosed from data assimilation. Journal of Physical Oceanography, 33, 485-498. https://doi.org/10.1175/1520-0485(2003)033<0485:IOWMTD>2.0.CO;2

Garcia, E. S., Sandwell, D. T., \& Smith, W. H. F. (2014). Retracking CryoSat-2, Envisat and Jason-1 radar altimetry waveforms for improved gravity field recovery. Geophysical Journal International, 196(3), 1402-1422. https://doi.org/10.1093/gji/ggt469

Gilardoni, M., Reguzzoni, M., \& Sampietro, D. (2015). GECO: A global gravity model by locally combining GOCE data and EGM2008. Studia Geophysica Et Geodaetica, 60(2), 228-247. https://doi.org/10.1007/s11200-015-1114-14

Griesel, A., Mazloff, M. R., \& Gille, S. T. (2012). Mean dynamic topography in the Southern Ocean: Evaluating Antarctic circumpolar current transport. Journal of Geophysical Research, 117, C01020. https://doi.org/10.1029/2011JC007573

Gruber, T., Rummel, R., Abrikosov, O., \& Hees, V. R. (2014). GOCE level 2 product data handbook, GO-MA-HPF-GS-0110, issue 4.2. Retrieved from https://earth.esa.int/documents/10174/1650485/GOCE_Product_Data_Handbook_Level-2

Hipkin, R. G., Haines, K., Beggan, C., Bingley, R., Hernandez, F., Holt, J., \& Baker, T. (2004). The geoid EDIN2000 and mean sea surface topography around the British Isles. Geophysical Journal International, 157(2), 565-577. https://doi.org/10.1111/j.1365-246X.2004.01989.x

Huang, J. (2017). Determining coastal mean dynamic topography by geodetic methods. Geophysical Research Letters, 44(21), 11125-11128. https://doi.org/10.1002/2017GL076020

Hunegnaw, A., Hipkin, R. G., Edwards, J., \& Mork, K. A. (2009). Absolute flow field estimation for the Nordic seas from combined gravimetric, altimetric, and in situ data. Journal of Geophysical Research, 114, C02022. https://doi.org/10.1029/2008JC004797

Hunegnaw, A., Siegismund, F., Hipkin, R., \& Mork, K. A. (2009). A method of error adjustment for marine gravity with application to Mean Dynamic Topography in the northern North Atlantic. Journal of Geodesy, 83, 161-174. https://doi.org/10.1007/s00190-008-0249-2

Hwang, C., Guo, J., Deng, X., Hsu, H. Y., \& Liu, Y. (2006). Coastal gravity anomalies from retracked Geosat/GM altimetry: Improvement, limitation and the role of airborne gravity data. Journal of Geodesy, 80(4), 204-216. https://doi.org/10.1007/s00190-006-0052-x

Hwang, C., \& Sung, A. C. (2000). Circulations and eddies over the South China Sea derived from topex/poseidon altimetry. Journal of Geophysical Research, 105(C10), 23943-23965. https://doi.org/10.1029/2000JC900092

Idžanović, M., Ophaug, V., \& Andersen, O. B. (2017). The coastal mean dynamic topography in Norway observed by CryoSat-2 and GOCE. Geophysical Research Letters, 44(11), 5609-5617. https://doi.org/10.1002/2017GL073777

Jayne, S. R. (2006). Circulation of the North Atlantic Ocean from altimetry and the gravity recovery and climate experiment geoid. Journal of Geophysical Research, 111, C03005. https://doi.org/10.1029/2005JC003128

Klees, R., Tenzer, R., Prutkin, I., \& Wittwer, T. (2008). A data-driven approach to local gravity field modelling using spherical radial basis functions. Journal of Geodesy, 82(8), 457-471. https://doi.org/10.1007/s00190-007-0196-3

Knudsen, P., Bingham, R., Andersen, O. B., \& Rio, M. H. (2011). A global mean dynamic topography and ocean circulation estimation using a preliminary GOCE gravity model. Journal of Geodesy, 85(11), 861-879. https://doi.org/10.1007/s00190-011-0485-8

Knudsen, P., Forsberg, R., Andersen, O., Solheim, D., Hipkin, R., Haines, K., et al. (2004). The gocina project-an overview and status. Proceedings of the second international GOCE user workshop "GOCE, the Geoid and Oceanography”, ESA-ESRIN.

Koch, K. R., \& Kusche, J. (2002). Regularization of geopotential determination from satellite data by variance components. Journal of Geodesy, 76(5), 259-268. https://doi.org/10.1007/s00190-002-0245-x

Kusche, J. (2003). A Monte-Carlo technique for weight estimation in satellite geodesy. Journal of Geodesy, 76(11), 641-652. https://doi. $\operatorname{org} / 10.1007 / \mathrm{s} 00190-002-0302-5$ 
Kvas, A., Brockmann, J. M., Krauss, S., Schubert, T., Gruber, T., Meyer, U., et al. (2021). GOCO06s - A satellite-only global gravity field model. Earth System Science Data, 13(1), 99-118. https://doi.org/10.5194/essd-13-99-2021

Li, J., Wang, G., Xue, H., \& Wang, H. (2019). A simple predictive model for the eddy propagation trajectory in the northern South China Sea. Ocean Science, 15(2), 401-412. https://doi.org/10.5194/os-15-401-2019

Lieb, V., Schmidt, M., Dettmering, D., \& Börger, K. (2016). Combination of various observation techniques for regional modeling of the gravity field. Journal of Geophysical Research: Solid Earth, 121, 3825-3845. https://doi.org/10.1002/2015jb012586

Lu, B., Barthelmes, F., Petrovic, S., Förste, C., Flechtner, F., Luo, Z., et al. (2017). Airborne gravimetry of GEOHALO mission: Data processing and gravity field modeling. Journal of Geophysical Research: Solid Earth, 122(12), 10586-10610. https://doi.org/10.1002/2017JB014425

Lyu, K., Yang, X. Y., Zheng, Q., Wang, D., \& Hu, J. (2016). Intraseasonal variability of the winter western boundary current in the South China Sea using satellite data and mooring observations. IEEE Journal of Selected Topics in Applied Earth Observations and Remote Sensing, 9(11), 5079-5088. https://doi.org/10.1109/JSTARS.2016.2553049

Mayer-Gürr, T., Kvas, A., Klinger, B., Rieser, D., Zehentner, N., Pail, R., et al. (2015). The combined satellite gravity field model GOCO05s. EGU general assembly.

McAdoo, D. C., Farrell, S. L., Laxon, S., Ridout, A., Zwally, H. J., \& Yi, D. (2013). Gravity of the Arctic Ocean from satellite data with validations using airborne gravimetry: Oceanographic implications. Journal of Geophysical Research: Oceans, 118, 917-930. https://doi. org/10.1002/jgrc.20080

Mulet, S., Rio, M. H., Etienne, H., Artana, C., Cancet, M., Dibarboure, G., et al. (2021). The new CNES-CLS18 global mean dynamic topography. Ocean Science, 17(3), 789-808. https://doi.org/10.5194/os-17-789-2021

Olsen, D. (2010). GT-1A and GT-2A airborne gravimeters: Improvements in design, operation and processing from 2003 to 2010. Book: Airborne gravity 2010, geoscience Australia and the geological survey of New South Wales.

Omang, O. C. D., \& Forsberg, R. (2000). How to handle topography in practical geoid determination: Three examples. Journal of Geodesy, 74(6), 458-466. https://doi.org/10.1007/s001900000107

Pail, R., Bruinsma, S., Migliaccio, F., Förste, C., Goiginger, H., Schuh, W. D., et al. (2011). First GOCE gravity field models derived by three different approaches. Journal of Geodesy, 85(11), 819-843. https://doi.org/10.1007/s00190-011-0467-x

Pail, R., Goiginger, H., Schuh, W.-D., Höck, E., Brockmann, J. M., Fecher, T., et al. (2010). Combined satellite gravity field model GOCO01S derived from GOCE and GRACE. Geophysical Research Letters, 37, L20314. https://doi.org/10.1029/2010GL044906

Panet, I., Kuroishi, Y., \& Holschneider, M. (2011). Wavelet modelling of the gravity field by domain decomposition methods: An example over Japan. Geophysical Journal International, 184(1), 203-219. https://doi.org/10.1111/j.1365-246X.2010.04840.x

Pavlis, N. K., Holmes, S. A., Kenyon, S. C., \& Factor, J. K. (2012). The development and evaluation of Earth Gravitational Model (EGM2008). Journal of Geophysical Research, 117, B04406. https://doi.org/10.1029/2011JB008916

Pavlis, N. K., Holmes, S. A., Kenyon, S. C., \& Factor, J. K. (2013). Correction to "The development and evaluation of the Earth Gravitational Model 2008 (EGM2008)”. Journal of Geophysical Research: Solid Earth, 118(5), 2633. https://doi.org/10.1029/jgrb.50167

Rio, M. H., Guinehut, S., \& Larnicol, G. (2011). New CNES-CLS09 global mean dynamic topography computed from the combination of GRACE data, altimetry, and in situ measurements. Journal of Geophysical Research, 116, C07018. https://doi.org/10.1029/2010JC006505

Rio, M. H., Mulet, S., \& Picot, N. (2014). Beyond GOCE for the ocean circulation estimate: Synergetic use of altimetry, gravimetry, and in situ data provides new insight into geostrophic and Ekman currents. Geophysical Research Letters, 41(24), 8918-8925. https://doi. org/10.1002/2014GL061773

Rummel, R., Balmino, G., Johannessen, J., Visser, P., \& Woodworth, P. (2002). Dedicated gravity field missions-Principle and aims. Journal of Geodynamics, 33(1), 3-20. https://doi.org/10.1016/S0264-3707(01)00050-3

Sandwell, D. T., Garcia, E., Soofi, K., Wessel, P., \& Smith, W. H. F. (2013). Towards 1mGal global marine gravity from CryoSat-2, Envisat, and Jason-1. The Leading Edge, 32(8), 892-899. https://doi.org/10.1190/tle32080892.1

Sandwell, D. T., Müller, R. D., Smith, W. H. F., Garcia, E., \& Francis, R. (2014). New global marine gravity model from CryoSat-2 and Jason-1 reveals buried tectonic structure. Science, 346(6205), 65-67. https://doi.org/10.1126/science.1258213

Schaeffer, P., Faugére, Y., Legeais, J. F., Ollivier, A., Guinle, T., \& Picot, N. (2012). The CNES_CLS11 global mean sea surface computed from 16 years of satellite altimeter data. Marine Geodesy, 35, 3-19. https://doi.org/10.1080/01490419.2012.718231

Scharroo, R., Leuliette, E. W., Lillibridge, J. L., Byrne, D., Naeije, M. C., \& Mitchum, G. T. (2013). RADS: Consistent multi-mission products. Proceedings of the symposium on 20 Years of progress in radar altimetry.

Schwabe, J., \& Scheinert, M. (2014). Regional geoid of the Weddell Sea, Antarctica, from heterogeneous ground-based gravity data. Journal of Geodesy, 88, 821-838. https://doi.org/10.1007/s00190-014-0724-x

Skourup, H., Farrell, S. L., Hendricks, S., Ricker, R., Armitage, T. W. K., Ridout, A., et al. (2017). An assessment of state-of-the-art mean sea surface and geoid models of the Arctic Ocean: Implications for sea ice freeboard retrieval. Journal of Geophysical Research: Oceans, 122, 8593-8613. https://doi.org/10.1002/2017JC013176

Solheim, D., Omang, O. C., Hunegnaw, A., Drange, H., Johannessen, J., Siegismund, F., et al. (2007). The OCTAS project, the geoid, the mean sea surface and the mean dynamic topography. Proceedings of the 3rd international GOCE user workshop. Frascati, Italy.

Tapley, B. D., Bettadpur, S., Watkins, M., \& Reigber, C. (2004). The gravity recovery and climate experiment: Mission overview and early results. Geophysical Research Letters, 31, L09607. https://doi.org/10.1029/2004GL019920

Tapley, B. D., Chambers, D. P., Bettadpur, S., \& Ries, J. C. (2003). Large scale ocean circulation from the GRACE GGM01 geoid. Geophysical Research Letters, 30(22), 2163. https://doi.org/10.1029/2003GL018622

Tenzer, R., \& Foroughi, I. (2018). Effect of the mean dynamic topography on the Geoid-to-Quasigeoid separation offshore. Marine Geodesy, 41(4), 368-381. https://doi.org/10.1080/01490419.2018.1452810

Volkov, D. L., \& Zlotnicki, V. (2012). Performance of GOCE and GRACE-derived mean dynamic topographies in resolving Antarctic Circumpolar Current fronts. Ocean Dynamics, 62(6), 893-905. https://doi.org/10.1007/s10236-012-0541-9

Weatherall, P., Marks, K. M., Jakobsson, M., Schmitt, T., Tani, S., Arndt, J. E., et al. (2015). A new digital bathymetric model of the world's oceans. Earth Space Science, 2, 331-345. https://doi.org/10.1002/2015EA000107

Woodworth, P. L., Hughes, C. W., Bingham, R. W., \& Gruber, T. (2012). Towards worldwide height system unification using ocean information. Journal of Geodetic Science, 2(4), 302-318. https://doi.org/10.2478/v10156-012-004-8

Wu, Y., Abulaitijiang, A., Featherstone, W. E., McCubbine, J. C., \& Andersen, O. B. (2019). Coastal gravity field refinement by combining airborne and ground-based data. Journal of Geodesy, 93, 2569-2584. https://doi.org/10.1007/s00190-019-01320-3

Wu, Y., Luo, Z., Chen, W., \& Chen, Y. (2017). High-resolution regional gravity field recovery from Poisson wavelets using heterogeneous observational techniques. Earth Planets and Space, 69(34), 1-15. https://doi.org/10.1186/s40623-017-0618-2

Wu, Y., Zhou, H., Zhong, B., \& Luo, Z. (2017). Regional gravity field recovery using the GOCE gravity gradient tensor and heterogeneous gravimetry and altimetry data. Journal of Geophysical Research: Solid Earth, 122(8), 6928-6952. https://doi.org/10.1002/2017JB014196 
Yan, C., Zhu, J., \& Xie, J. (2010). An ocean reanalysis system for the joining area of Asia and Indian-Pacific Ocean. Atmospheric and Oceanic Science Letters, 3, 81-86. https://doi.org/10.1080/16742834.2010.11446848

Yan, C., Zhu, J., \& Xie, J. (2015). An ocean data assimilation system in the Indian Ocean and West Pacific Ocean. Advances in Atmospheric Sciences, 32(11), 1460-1472. https://doi.org/10.1007/s00376-015-4121-Z

Yang, H., Liu, Q., Liu, Z., Wang, D., \& Liu, X. (2002). A general circulation model study of the dynamics of the upper ocean circulation of the South China Sea. Journal of Geophysical Research, 107(C7), 3085. https://doi.org/10.1029/2001JC001084

Zingerle, P., Pail, R., Gruber, T., \& Oikonomidou, X. (2019). The experimental gravity field model XGM2019e. GFZ Data Services. https:// doi.org/10.5880/ICGEM.2019.007

Zuo, H., Balmaseda, M. A., \& Mogensen, K. (2017). The new eddy-permitting ORAP5 ocean reanalysis: Description, evaluation and uncertainties in climate signals. Climate Dynamics, 49(3), 791-811. https://doi.org/10.1007/s00382-015-2675-1 